\title{
ALTERATIONS OF THE SUBCHONDRAL BONE IN OSTEOCHONDRAL REPAIR - TRANSLATIONAL DATA AND CLINICAL EVIDENCE
}

\author{
Patrick Orth $^{1,2}$, Magali Cucchiarini ${ }^{1}$, Dieter Kohn ${ }^{2}$ and Henning Madry ${ }^{1,2, *}$ \\ ${ }^{1}$ Center of Experimental Orthopaedics, Saarland University, Homburg, Germany \\ ${ }^{2}$ Department of Orthopaedic Surgery, Saarland University Medical Center, Homburg, Germany
}

\begin{abstract}
Alterations of the subchondral bone are pathological features associated with spontaneous osteochondral repair and with articular cartilage repair procedures. The aim of this review is to discuss their incidence, extent and relevance, focusing on recent knowledge gained from both translational models and clinical studies of articular cartilage repair. Efforts to unravel the complexity of subchondral bone alterations have identified (1) the upward migration of the subchondral bone plate, (2) the formation of intralesional osteophytes, (3) the appearance of subchondral bone cysts, and (4) the impairment of the osseous microarchitecture as potential problems. Their incidence and extent varies among the different small and large animal models of cartilage repair, operative principles, and over time. When placed in the context of recent clinical investigations, these deteriorations of the subchondral bone likely are an additional, previously underestimated factor that influences the long-term outcome of cartilage repair strategies. Understanding the role of the subchondral bone in both experimental and clinical articular cartilage repair thus holds great promise of being translated into further improved cell- or biomaterial-based techniques to preserve and restore the entire osteochondral unit.
\end{abstract}

Keywords: Subchondral bone; microarchitecture; marrow stimulation; microfracture; subchondral drilling; abrasion arthroplasty.

\footnotetext{
*Address for correspondence:

Henning Madry, MD

Center of Experimental Orthopaedics

Saarland University

Kirrberger Strasse, Building 37

D-66421 Homburg, Germany
}

Telephone Number: +4968411624515

FAX Number: +496841 1624988

E-mail: henning.madry@uks.eu

\section{Introduction}

A complete restoration of the osteochondral unit is the goal of all articular repair techniques (Brittberg et al., 1994; Johnson, 1986; Pridie, 1959; Steadman et al., 2001). Traditionally, a focus was placed on the cartilaginous repair tissue, but it is now clear that complex structural changes of the subchondral bone are associated with spontaneous osteochondral repair and with the use of cartilage repair procedures (Madry et al., 2010). They include (1) the upward migration of the subchondral bone plate, (2) the formation of intralesional osteophytes, (3) the appearance of subchondral bone cysts, and (4) the impairment of the osseous microarchitecture (Fig. 1). There is accumulating experimental evidence for these subchondral bone alterations in small (Aroen et al., 2006; Chen et al., 2009; Chen et al., 2011a; Heir et al., 2012; Marchand et al., 2011; Marchand et al., 2012; Nam et al., 2004; Qiu et al., 2003) and large preclinical animal models (Dorotka et al., 2005; Frisbie et al., 1999; Hanie et al., 1992; Hoemann et al., 2005; Howard et al., 1994; Ishimaru et al., 1992; Lane et al., 2004; Orth et al., 2012b; Vachon et al., 1986) of cartilage defects. Supporting these findings, such pathological alterations were also reported in up to one third of patients treated with microfracture (Kreuz et al., 2006; Mithoefer et al., 2005; Saris et al., 2009). Moreover, autologous chondrocyte implantation (ACI) for articular cartilage defects previously treated with marrow stimulation techniques has a three-fold higher failure rate than for untreated defects (Cole et al., 2011; Minas et al., 2009; Vasiliadis et al., 2010). In addition, upward migration of the subchondral bone plate or the development of intralesional osteophytes might also occur spontaneously in large, full-thickness chondral lesions in patients (Henderson and La Valette, 2005), possibly playing a role in the degeneration of the cartilaginous repair tissue (Cole et al., 2011; Minas et al., 2009; Vasiliadis et al., 2010). These studies point to the need to account for the complex role of subchondral bone alterations associated with osteochondral repair.

The aim of this review is to discuss the incidence, extent, and relevance of structural alterations of the subchondral bone, focusing on recent knowledge gained from both translational models and clinical studies of celland/or biomaterial-based procedures for cartilage repair.

\section{Applied anatomy of the osteochondral unit}

The subchondral bone is the layer of bone that lies immediately below the calcified zone of the articular cartilage (Fig. 1). Together with the cartilage, it forms the 

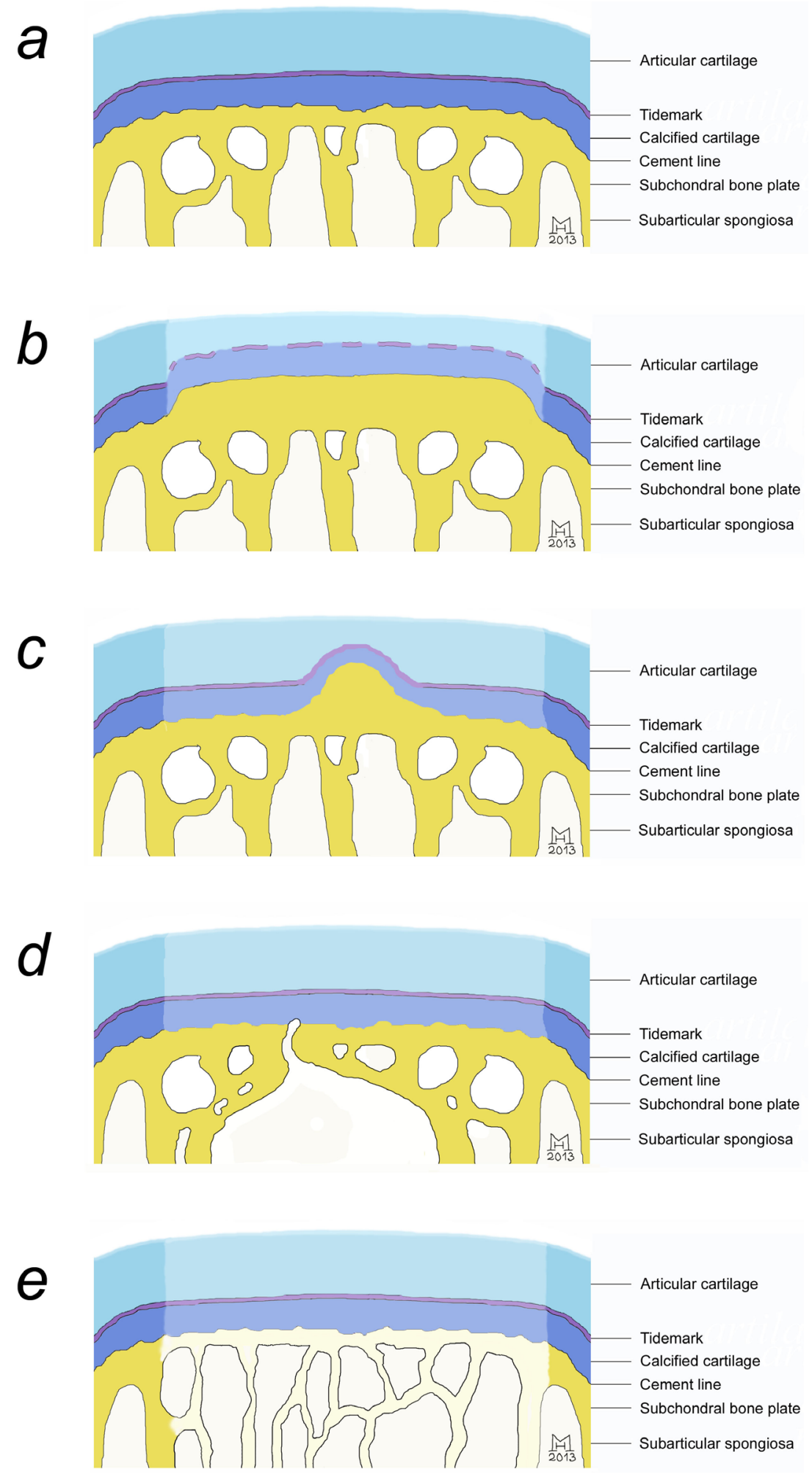

Fig. 1. Synopsis of the structures constituting the normal osteochondral unit (a) and of the complex alterations of the subchondral bone during osteochondral repair (b-e; osteochondral repair tissue can be identified by its less intense colour). These alterations occur sporadically and are not ineluctable consequences of subchondral bone plate perforation. They may be categorised as (b) the generalised upward migration of the subchondral bone plate, (c) the formation of focal intralesional osteophytes, (d) the appearance of subchondral bone cysts, and (e) the impairment of the microarchitecture of the subchondral bone. Note the upward migration of the subchondral bone plate (b), leading to a consecutive thinning of the articular cartilage layer and to an extension of the subchondral bone plate volume into the cartilaginous repair tissue. Intralesional osteophytes (c) are defined as focal newly formed bone located apical to the original cement line. An intralesional osteophyte can be either located in a central or peripheral location within the articular cartilage defect. The subchondral bone cyst (d) has its largest expansion within the subarticular spongiosa and is surrounded by a sclerotic rim. Note also the changes in the subchondral bone microarchitecture (e), for example a generalised thinning of the subchondral bone plate, a reduced trabecular thickness, and an overall decreased subchondral bone volume. 
osteochondral unit (Madry et al., 2010). The basophilic line on histological sections that separates hyaline articular cartilage from the underlying calcified cartilage is called the tidemark (Broom and Poole, 1982), while the line that separates the calcified cartilage from the subchondral bone plate is called the cement line (Fig. 1) (Madry et al., 2010). Two parts constitute the subchondral bone: The subchondral bone plate is composed of cancellous bone, consisting of bone plates which join together to enclose narrow intervening spaces. While denser than the subarticular spongiosa, the subchondral bone plate is relatively thin in normal human subchondral bone (Hunziker et al., 2002). It is broader and more dense in osteoarthritic joints and in some animals (Frisbie et al., 1999). The intervening spaces are gradually enlarged and become elongated in a direction parallel to the diaphysis in deeper regions of the subchondral bone, forming the subarticular spongiosa (Fig. 1) (Madry et al., 2010). When the calcified cartilage layer is surgically removed (e.g. during the debridement of a cartilage defect prior to marrow stimulation), vascular canals of the subchondral region may be opened (Drobnic et al., 2010).

\section{Spontaneous and therapeutic osteochondral repair}

\section{Principles of spontaneous osteochondral repair}

Osteochondral defects disrupt the structural integrity of the subchondral bone, but the natural history of the restoration of the subchondral bone plate in these defects is not well understood (Gomoll et al., 2010b; Madry, 2010; Madry et al., 2010; Orth et al., 2013a; Pape et al., 2010). Besides constituting the new cartilaginous repair tissue, mesenchymal cells in the deeper regions of the defect also differentiate into osteocytes (Jackson et al., 2001; Shapiro et al., 1993), resulting in the formation of immature bone that usually restores the original level of the subchondral bone in a distinct chronological order (Orth et al., 2012a). Over time, however, this new subchondral bone may advance toward the joint space, and intralesional osteophytes might form (Orth et al., 2012b).

\section{Marrow stimulation techniques}

Marrow stimulation procedures such as microfracture (Steadman et al., 2001), subchondral drilling (Pridie, 1959) and abrasion arthroplasty (Johnson, 1986) are important and commonly applied first-line treatments for symptomatic small articular cartilage defects (Gomoll et al., 2010a; Grana, 2000; Moran et al., 2012; Safran and Seiber, 2010; Williams and Brophy, 2008). Altogether, these measures establish a communication of the cartilage defect with the bone marrow, either by focal perforation of the cement line with awls (microfracture) or drill bits (subchondral drilling) or by generalised abrasion to a maximal depth of 1-2 mm (Johnson, 1986; Johnson 2001) of the subchondral bone plate with round or cylindrical burrs (abrasion arthroplasty). These discrepancies in the surgical technique may yield differences in the subchondral bone response. Depending on the intra-articular location of the cartilage defect, one surgical treatment option might be superior to another with regard to technical feasibility. The common aim of these techniques is to allow mesenchymal cells from the underlying cavity to migrate into the defect (Gomoll et al., 2010b; Tetteh et al., 2012). Subsequently, the remodelling of the subchondral bone proceeds along with the induction of chondrogenesis and fibrocartilaginous repair (Shapiro et al., 1993).

\section{Autologous chondrocyte implantation}

$\mathrm{ACI}$ is a two-stage surgical procedure, chiefly indicated for large focal cartilage defects (Brittberg et al., 1994). After arthroscopic removal of a cartilage biopsy, the cultured chondrocytes are implanted during a second operation. While initially a periosteal flap was sewn over the defect to hold the cell suspension in place, chondrocytes are currently incorporated into biodegradable scaffolds (Batty et al., 2011; Safran and Seiber, 2010). Similar to marrow stimulation procedures, the calcified cartilage layer at the bottom of the defect is completely removed prior to implantation. In contrast, however, care is taken not to induce bleeding from the subchondral bone. Interestingly, large animal models of cell-based cartilage repair show that besides the implanted chondrocytes, cells from the subchondral bone also participate in the formation of the repair tissue (Dell'Accio et al., 2003; Jackson et al., 2001).

\section{Insights from translational models}

\section{Upward migration of the subchondral bone plate}

Upward migration of the subchondral bone plate is defined as the expansion of the osteochondral junction above its original level with resulting elevation of the subchondral bone plate into the cartilaginous repair tissue (Orth et al., 2012a) (Fig. 2).

In a rabbit model of spontaneous osteochondral repair, the subchondral bone reconstitution proceeded in a temporarily well-defined, distinct geometrical repair pattern (Orth et al., 2012a). After six months, the subchondral bone is reconstituted to nearly normal levels. Then, the level of the new subchondral bone plate gradually advances above its native position and the cartilaginous repair tissue degrades (Orth et al., 2012a; Qiu et al., 2003) (Table 1) (Fig. 3). Of note, both processes advance at a different pace, as no statistical correlation was detected between articular cartilage repair and subchondral bone reconstitution (Orth et al., 2012a; Orth et al., 2013a).

A significant upward migration of the rabbit subchondral bone plate has also been observed 3 (Chen et al., 2011a) or 9 months (Aroen et al., 2006) after subchondral drilling and microfracture. In sheep, elevation of the subchondral bone plate beyond the former level of the tidemark was reported for chondral defects treated by microfracture after 1 year (Dorotka et al., 2005). While this was not confirmed in another sheep model of drilled full-thickness cartilage defects after 6 months (Orth et al., 2012b), in horses $50 \%$ of drilled chondral defects exhibited elevation of the subchondral bone into the defect site (Shamis et al., 1989) (Table 1).

In late stage osteoarthritis, the subchondral bone plate similarly advances towards the joint surface while the overlying cartilage layer narrows (Burr, 2004; Henrotin 
et al., 2009; Lajeunesse et al., 1999), possibly due to metaplasia of the deep layer of the articular cartilage (Shapiro et al., 1993). Several investigations speculated that such an upward migration of the subchondral bone plate might be the primary cause for subsequent cartilage degeneration in osteoarthritis (Bullough and Jagannath, 1983; Green et al., 1970; Jeffery, 1973; Radin et al., 1991). Thickening of the subchondral bone plate increases its stiffness, and the thickness variation generated uneven pressure distribution as well as shear forces in the articular cartilage repair tissue that may initiate degeneration (Qiu et al., 2003). In good agreement, Shahgaldi et al. (1991) emphasised that advancement of the subchondral hard tissue by only a few millimetres towards the articular surface is sufficient to cause injury to articular cartilage by loss of joint resilience at peak loading. Likewise, Qiu et al. (2003) demonstrated that in the presence of an advanced subchondral plate, repaired surface layers showed reduced Safranin O staining, increased separation splits at the boundary with neighbouring cartilage, softening, and eventual degradation.

\section{Intralesional osteophytes}

Intralesional osteophytes (Fig. 4) are defined as focal, newly-formed bone located apical to the original cement line and projected into the cartilaginous repair tissue layer (Cole et al., 2011; Orth et al., 2012b). Contrary to genuine chondro-osteophytes, which arise in the periosteum close to diarthrodial joints, intralesional osteophytes per se are not covered with a fibrocartilaginous cap (van der Kraan and van den Berg, 2007).

According to the observed articular cartilage degeneration overlying a generalised thickened subchondral

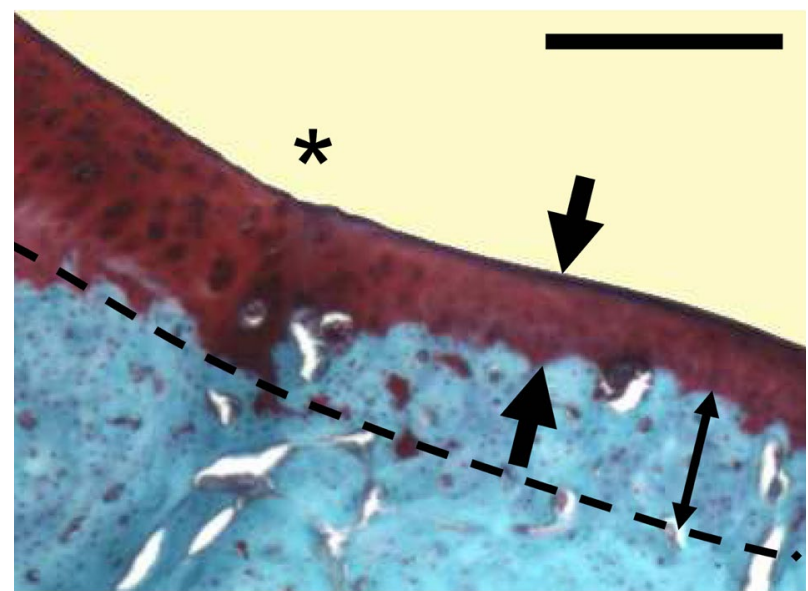

Fig. 2. Histological image of an untreated and spontaneously repaired osteochondral defect (diameter: $3.2 \mathrm{~mm}$; depth: $5.0 \mathrm{~mm}$ ) 1 year after its creation in the femoral trochlea of a 14-week old Chinchilla bastard rabbit stained with Safranin O/fast green. The integration site between repair tissue and native cartilage is still identifiable (star). The dotted line represents the normal position of the osteochondral junction. Thickening and upward migration of the subchondral bone plate (slim arrow) results in narrowing of the repair tissue layer covering the upwardly migrated subchondral bone (broad arrows). Scale bar: $1.0 \mathrm{~mm}$.

bone plate, the development of focal intralesional osteophytes may also put the overlying cartilaginous repair tissue at further risk of degeneration (Fortier et al., 2012). No data exist to date regarding the effect of focal intralesional osteophytes on cartilage degeneration.

\section{Articular cartilage repair}

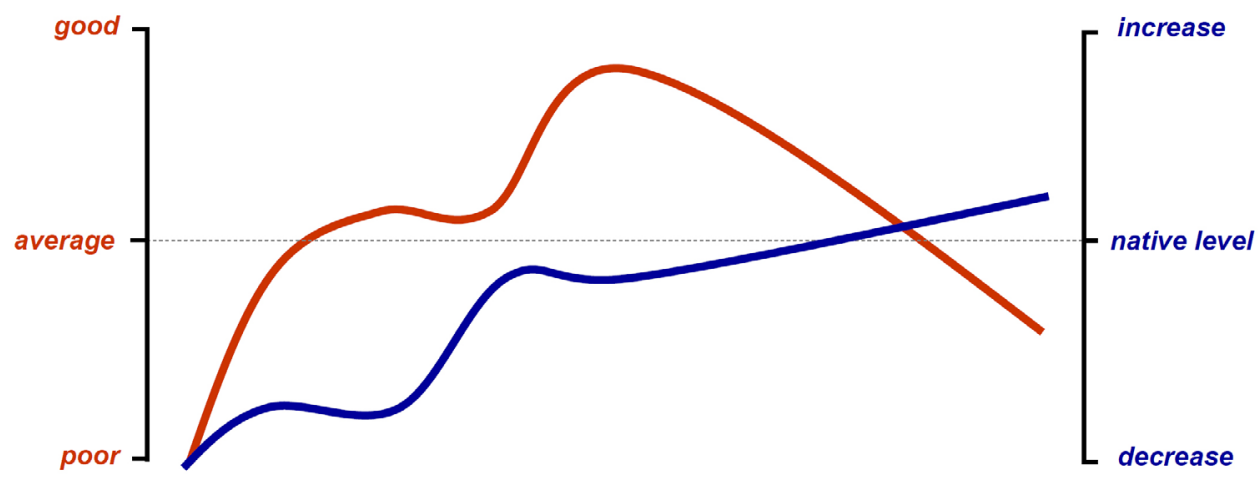

Subchondral bone reconstitution

\section{Cartilage defect creation}

\section{1 year postoperatively}

Fig. 3. Chronological sequence of the reconstitution of the subchondral bone and the quality of articular cartilage repair during the spontaneous repair of untreated osteochondral defects (diameter: $3.2 \mathrm{~mm}$; depth: $5.0 \mathrm{~mm}$ ) in the femoral trochlea of 14-week old Chinchilla bastard rabbits. Note that at early stages after osteochondral defect creation, both subchondral bone and articular cartilage repair are of inferior quality. Over a period of about six months, articular cartilage repair improves, and the subchondral bone is reconstituted to nearly normal levels. After one year, however, the subchondral bone advances above its native position and the repaired articular cartilage degrades in the lapine model. Potentially, inter-species differences in these chronological sequences may exist. Adapted from Orth et al. (2012a). 
Table 1. Overview of reported subchondral bone alterations in experimental animal models of spontaneous osteochondral repair and following different articular cartilage repair procedures.

\begin{tabular}{|c|c|c|c|c|c|c|c|c|}
\hline Pathology & Surgical procedure & $\begin{array}{c}\text { Animal } \\
\text { model }\end{array}$ & Detection method & $\begin{array}{c}\text { Follow- } \\
\text { up } \\
\text { [months] }\end{array}$ & $\begin{array}{c}\text { Number of } \\
\text { animals }\end{array}$ & $\begin{array}{l}\text { Incidence } \\
\text { per defect }\end{array}$ & Distance & Reference \\
\hline \multirow[t]{19}{*}{$\begin{array}{l}\text { Upward } \\
\text { migration }\end{array}$} & $\begin{array}{c}\text { none } \\
\text { (spontaneous } \\
\text { osteochondral } \\
\text { repair) }\end{array}$ & rabbit & histomorphometry & 2 & $\underline{14}$ & n.a. & $-0.79 \mathrm{~mm}$ & (Qiu et al., 2003) \\
\hline & & & & 8 & 7 & n.a. & $+0.13 \mathrm{~mm}$ & \\
\hline & $\begin{array}{c}\text { none } \\
\text { (spontaneous } \\
\text { osteochondral } \\
\text { repair) }\end{array}$ & rabbit & histomorphometry & 0.8 & $\underline{12}$ & n.a. & $-0.57 \mathrm{~mm}$ & (Orth et al., 2012a) \\
\hline & & & & 12 & $\underline{10}$ & n.a. & $+0.19 \mathrm{~mm}$ & \\
\hline & $\begin{array}{c}\text { none } \\
\text { (spontaneous } \\
\text { chondral repair) }\end{array}$ & rabbit & histomorphometry & 0.3 & $\underline{3}$ & n.a. & $-0.09 \mathrm{~mm}$ & (Aroen et al., 2006) \\
\hline & & & & 0.5 & $\underline{6}$ & n.a. & $-0.08 \mathrm{~mm}$ & \\
\hline & & & & 9 & $\underline{8}$ & n.a. & $-0.08 \mathrm{~mm}$ & \\
\hline & $\begin{array}{c}\text { none } \\
\text { (spontaneous } \\
\text { chondral repair) }\end{array}$ & sheep & histomorphometry & 4 & $\underline{3}$ & $0 \%$ & n.a. & (Dorotka et al., 2005) \\
\hline & & & & 12 & $\underline{4}$ & $0 \%$ & n.a. & \\
\hline & Drilling & rabbit & histomorphometry & 0.3 & $\underline{3}$ & n.a. & $-0.04 \mathrm{~mm}$ & (Aroen et al., 2006) \\
\hline & & & & 0.5 & $\underline{6}$ & n.a. & $+0.08 \mathrm{~mm}$ & \\
\hline & & & & 9 & $\underline{8}$ & n.a. & $+0.07 \mathrm{~mm}$ & \\
\hline & Drilling & rabbit & $\begin{array}{l}\text { histomorphometry } \\
\qquad / \mu \mathrm{CT}\end{array}$ & 3 & $\underline{8}$ & $38-50 \%$ & n.a. & (Chen et al., 2011) \\
\hline & Drilling & sheep & $\mu \mathrm{CT}$ & 6 & $\underline{19}$ & $0 \%$ & n.a. & (Orth et al., 2012b) \\
\hline & Microfracture & rabbit & $\begin{array}{l}\text { histomorphometry } \\
\qquad / \mu \mathrm{CT}\end{array}$ & 3 & $\underline{8}$ & $50 \%$ & n.a. & (Chen et al., 2011) \\
\hline & Microfracture & sheep & histomorphometry & 4 & $\underline{3}$ & $0 \%$ & n.a. & (Dorotka et al., 2005) \\
\hline & & & & 12 & $\underline{4}$ & $100 \%$ & n.a. & \\
\hline & $\begin{array}{c}\text { Microfracture and } \\
\text { ACI }\end{array}$ & sheep & histomorphometry & 4 & $\underline{3}$ & $0 \%$ & n.a. & (Dorotka et al., 2005) \\
\hline & & & & 12 & $\underline{4}$ & $100 \%$ & n.a. & \\
\hline \multirow[t]{2}{*}{$\begin{array}{l}\text { Intralesional } \\
\text { osteophyte }\end{array}$} & Drilling & sheep & histomorphometry & 3 & $\underline{5}$ & $100 \%$ & n.a. & (Ishimaru et al., 1992) \\
\hline & Drilling & sheep & $\mu \mathrm{CT}$ & 6 & $\underline{19}$ & $26 \%$ & n.a. & (Orth et al., 2012b) \\
\hline \multirow[t]{12}{*}{ Cyst } & $\begin{array}{c}\text { none } \\
\text { (spontaneous } \\
\text { osteochondral } \\
\text { repair) }\end{array}$ & horse & histomorphometry & 12 & $\underline{10}$ & n.a. & n.a. & (Howard et al., 1994) \\
\hline & $\begin{array}{c}\text { none } \\
\text { (spontaneous } \\
\text { osteochondral } \\
\text { repair) }\end{array}$ & horse & xeroradiography & 4 & $\underline{3}$ & n.a. & n.a. & (Hanie et al., 1992) \\
\hline & & & & 6 & $\underline{3}$ & n.a. & n.a. & \\
\hline & Drilling & rabbit & $\begin{array}{l}\text { histomorphometry } \\
\qquad / \mu \mathrm{CT}\end{array}$ & 3 & $\underline{8}$ & $41 \%$ & n.a. & (Chen et al., 2011) \\
\hline & Drilling & sheep & histomorphometry & 3 & $\underline{5}$ & $20 \%$ & n.a. & (Ishimaru et al., 1992) \\
\hline & Drilling & sheep & $\mu \mathrm{CT}$ & 6 & $\underline{19}$ & $63 \%$ & n.a. & (Orth et al., 2012b) \\
\hline & Drilling & horse & histology & 5 & $\underline{6}$ & $100 \%$ & n.a. & (Vachon et al., 1986) \\
\hline & Microfracture & rabbit & $\begin{array}{l}\text { histomorphometry } \\
\qquad / \mu \mathrm{CT}\end{array}$ & 3 & $\underline{8}$ & $25 \%$ & n.a. & (Chen et al., 2011) \\
\hline & Microfracture & sheep & histomorphometry & 6 & $\underline{6}$ & $83 \%$ & n.a. & (Hoemann et al., 2005) \\
\hline & Microfracture & horse & histomorphometry & 4 & $\underline{5}$ & $0 \%$ & n.a. & (Frisbie et al., 1999) \\
\hline & & & & 12 & $\underline{5}$ & $10 \%$ & n.a. & \\
\hline & $\begin{array}{c}\text { Microfracture } \\
\text { (chitosan-glycerol } \\
\text { phosphate/blood) }\end{array}$ & sheep & histomorphometry & 6 & $\underline{8}$ & $63 \%$ & n.a. & (Hoemann et al., 2005) \\
\hline
\end{tabular}

Positive values for the migration distance indicate an elevation of the subchondral bone plate above its native position (i.e. towards the joint line) while negative values indicate a position below its original location. n.a.: not available; $\mu \mathrm{CT}$ : micro computed tomography; ACI: autologous chondrocyte implantation. 
Fig. 4. A subchondral bone cyst (a; star) and an intralesional osteophyte (b; arrow) formed after subchondral drilling of full-thickness cartilage defects of medial femoral condyles in the sheep model, displayed on micro computed tomography images in the frontal plane. In this model, cysts (a) usually originate from the drillingcanal. Intralesional osteophytes (b) protrude into the cartilaginous repair tissue and originate from the former cement line. The joint surface is simulated by the curved white lines and the lateral and medial defect margins are indicated by white triangles (a, b). AC: articular cartilage; SBP: subchondral bone plate; SAS: subarticular spongiosa. Scale bars: $1.0 \mathrm{~mm}$.
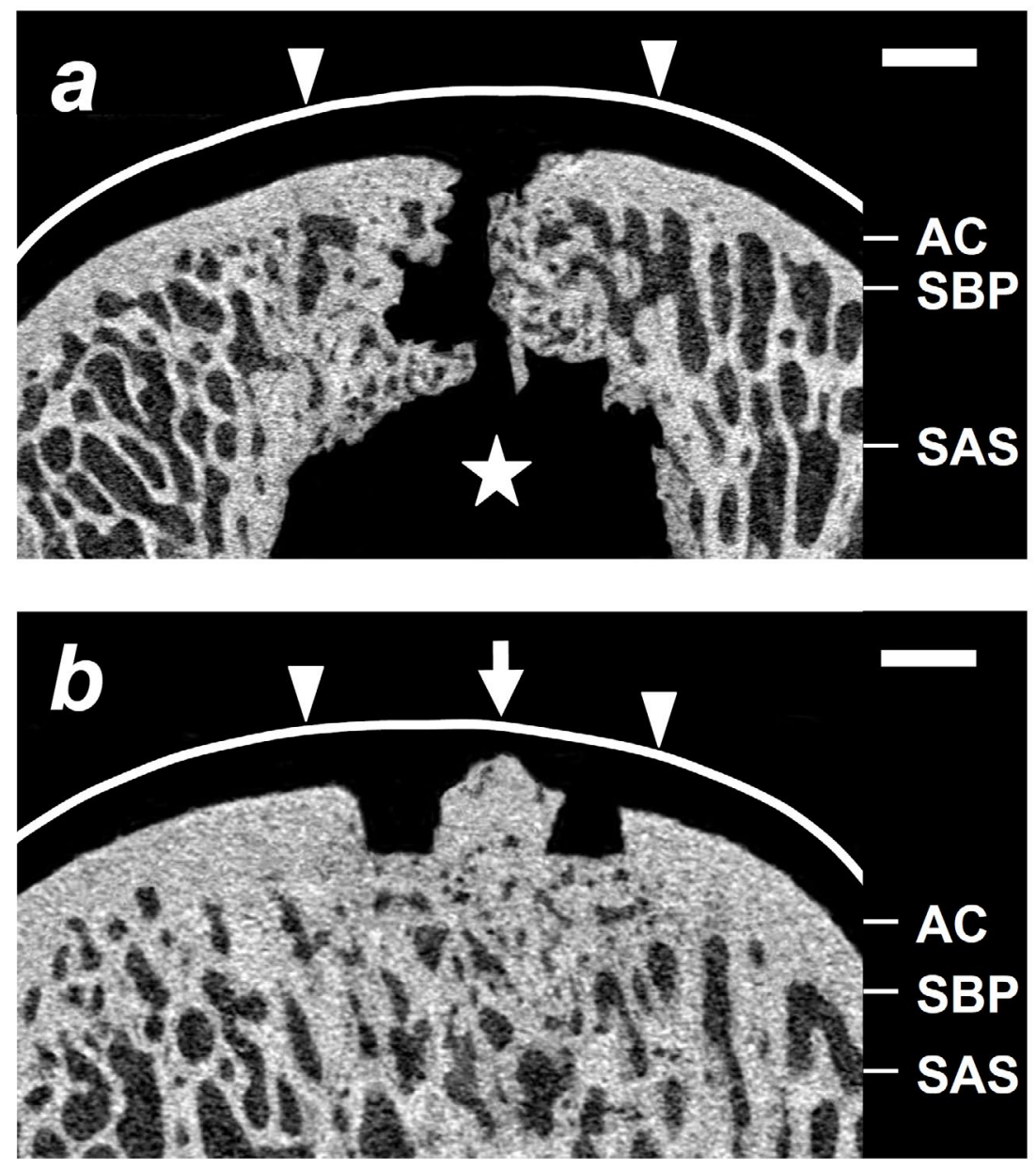

However, it is possible, in theory, that a cartilaginous repair tissue connected to such bone overgrowth may be more stable. In the sheep model, intralesional osteophyte formation was observed after 3 months in all temporomandibular joints that had received perforation of the subchondral bone plate (Ishimaru et al., 1992). Recent data revealed a $26 \%$ incidence of intralesional osteophyte formation 6 months following drilling of full-thickness chondral defects of ovine medial femoral condyles with immediate and full weight-bearing postoperatively (Orth et al., 2012b) (Table 1).

\section{Subchondral bone cysts}

Subchondral bone cysts (Fig. 4), an entity usually occurring in late-stage osteoarthritis (Pritzker et al., 2006), are also reported in conjunction with marrow stimulation procedures in translational animal models.

Microfracture holes, drill holes, or the generalised thinning of the subchondral bone plate following abrasion arthroplasty may induce pathological bone resorption and subchondral cyst formation (Fig. 4) in horses (Frisbie et al., 1999; Hanie et al., 1992; Howard et al., 1994; Vachon et al., 1986) and rabbits (Chen et al., 2011a) (Table 1). Ishimaru et al. (1992) observed subchondral cysts following perforation of the subchondral bone plate in the temporomandibular joint of sheep. By micro computed tomography $(\mu \mathrm{CT})$ assessment of ovine cartilage defects treated by deep drilling, subchondral bone cysts were found in $63 \%$ after 6 months (Orth et al., 2012b). Hoemann et al. (2005) reported on a decrease in subchondral cyst formation beneath microfracture-treated full-thickness chondral defects in sheep, by the additional transplantation of chitosan-glycerol phosphate-blood implants. Cysts have also been described in animal models following the implantation of proud (Pearce et al., 2001) or unstable (Hurtig et al., 2001; von Rechenberg et al., 2003) osteochondral transplants (Heir et al., 2012).

\section{Changes in subchondral bone microarchitecture}

The subchondral bone microarchitecture can be assessed by histomorphometric (Parfitt et al., 1987) or threedimensional radiological techniques (Feldkamp et al., 1989; Marchand et al., 2011; Orth et al., 2012b).

The physiological reaction to marrow stimulation procedures is described as early bone resorption followed by a remodelling process resembling fracture healing (Heir et al., 2012). The duration of this remodelling phase depends on the experimental model and ranges between 3 and 12 months (Dorotka et al., 2005; Lane et al., 2004; Nam et al., 2004).

The work of Hoemann and Buschmann (Chen et al., 2009; Chen et al., 2011a; Chen et al., 2011b; Marchand et al., 2011; Marchand et al., 2012) revealed that lapine subchondral bone surrounding drill holes remains morphologically intact at day 1 , while empty osteocyte lacunae surround microfracture holes (Chen et al., 2009). Regarding the drilling instrument itself, drills may be superior to Kirschner wires, which do not remove bone 
debris - thus possibly impeding the migration of stem cells (Chen et al., 2009). $\mu$ CT showed that microfracture induces subchondral bone compaction with increased bone mineral density and trabecular thickness in rabbits, whereas drilling left a normal bone structure (Chen et al., 2009). However, only $31 \%$ of the original lapine subchondral bone plate remained 1 day after subchondral microdrilling (Marchand et al., 2011). At 6 months, only partial restoration of the drilled subchondral bone plate was observed whereas the neighbouring subchondral plate had thickened, suggesting that drilling may also induce long-term changes in the adjacent rabbit subchondral bone (Marchand et al., 2012). Interestingly, compared with shallow drilling ( $2 \mathrm{~mm})$, deep drilling to $6 \mathrm{~mm}$ induced a larger volume of remodelling bone, which appeared beneficial for lapine cartilage repair after 3 months (Chen et al., 2011a; Chen et al., 2011b). Following an osteochondral injury, the microarchitecture of the subchondral bone can be improved by administration of bone-anabolic agents such as the 1-34 amino acid segment of the parathyroid hormone (Orth et al., 2013a). Regarding the long-term effect of subchondral drilling on the microarchitecture of the subchondral bone in sheep, significantly reduced bone volume (BV/TV), trabecular thickness, and bone mineral density (BMD) were reported after 6 months (Orth et al., 2012b). Interestingly, these changes were similar to patterns in osteoporosis and osteoarthritis: a decrease in BV/TV, BMD, and trabecular thickness is a typical finding in sheep (Mastbergen et al., 2008; Wu et al., 2008), dogs (Sniekers et al., 2008), or goats (Siu et al., 2004) suffering from osteoporosis or osteoarthritis. Of note, the relationship between repair bone architecture and the quality of the cartilage repair tissue is still the object of investigation by many different research groups using distinct approaches.

\section{Relevance of subchondral bone alterations for experimental cartilage repair}

The histological aspect of the fibrocartilaginous repair tissue in marrow-stimulated cartilage defects is well described (Fortier et al., 2012; Frisbie et al., 1999; Furukawa et al., 1980; Goebel et al., 2012; Jackson et al., 2001; Shapiro et al., 1993). In rabbits, the access of bone marrow elements to the lesions by microfracture (Heir et al., 2012) or drill holes (Aroen et al., 2006) caused an increased filling after 9 months, when compared to defects lacking such access (Shamis et al., 1989). These data were confirmed in the sheep model at 1 year (Dorotka et al., 2005). Besides quantity, the quality of the repair tissue may further be enhanced by implantation of chitosan-glycerol phosphate (Chevrier et al., 2007; Hoemann et al., 2005), thrombin-solidified chitosan (Marchand et al., 2012), or cell-seeded collagen matrices (Dorotka et al., 2005).

Comparing subchondral drilling with the microfracture technique, Chen et al. (2009) found a similar repair of fullthickness chondral defects in the lapine trochlear groove of rabbits. Interestingly, deep drilling $(6 \mathrm{~mm})$ elicited a greater defect fill, increased glycosaminoglycan and type II collagen content, and reduced type I collagen content of the repair tissue than shallow drilling $(2 \mathrm{~mm}$ ) (Chen et al., 2009).
The success of marrow stimulation for chondral lesions depends on the meticulous removal of the calcified cartilage layer (which is best achieved by open debridement with a curette) (Drobnic et al., 2010), improving the arthroscopic (4 months) and macroscopic (1 year) aspect of equine repair tissues, although not affecting histological, biochemical or imaging analyses (Frisbie et al., 2006). Interestingly, no effect of drill hole diameter ( 0.5 versus $0.9 \mathrm{~mm}$ ) on the quality of cartilage repair was seen 6 months after subchondral drilling in rabbits (Marchand et al., 2012).

\section{Clinical evidence of subchondral bone alterations}

Upward migration of the subchondral bone plate Particularly in clinical investigations, with lower image resolution techniques compared to experimental studies (Menetrey et al., 2010), differentiation between laminar upward migration of the entire subchondral bone plate (Fig. 5) and selective, localised formation of intralesional osteophytes (Fig. 6) is difficult to document. Several authors refer to both phenomena by the term "osseous overgrowth" (Kreuz et al., 2006; Minas et al., 2009; Mithoefer et al., 2005). Mithoefer et al. (2005) observed, by magnetic resonance imaging (MRI), thickening and

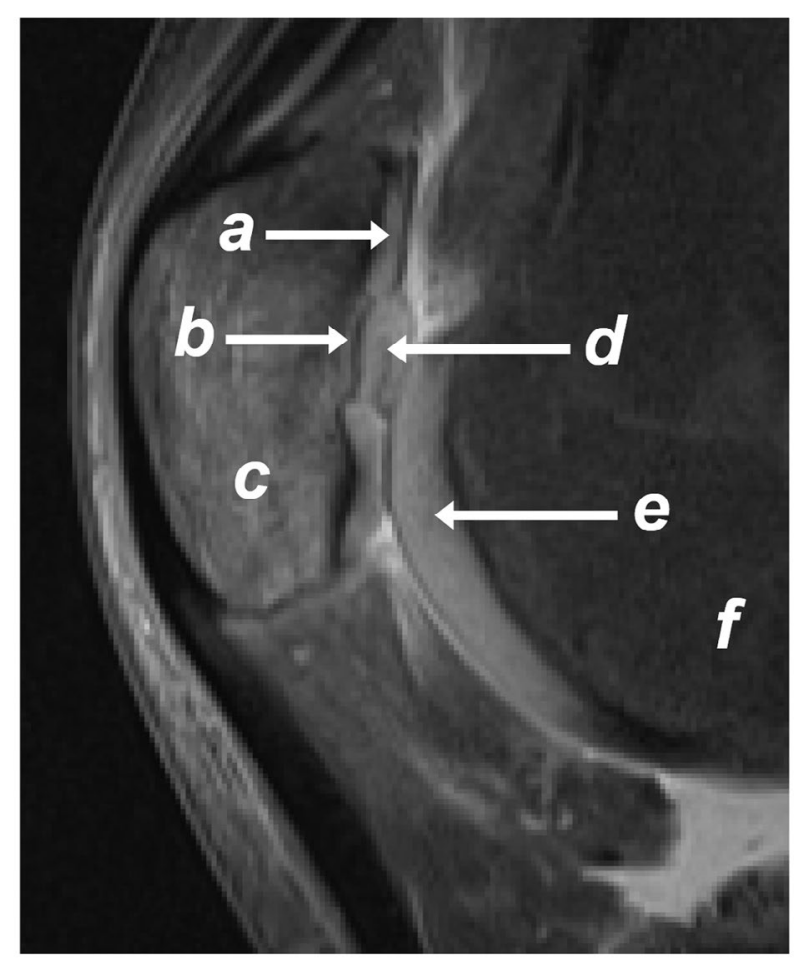

Fig. 5. Magnetic resonance image of the right knee joint of a 21-year-old man 6 months following arthroscopic abrasion arthroplasty of a chondral defect at the patella. Normal articular cartilage neighbouring the defect site can be identified proximal (a) and distal to the defect on the dorsal surface of the patella (c) as well as on the condylar circumference of the distal femur (f). Note the significant upward migration of the subchondral bone plate within the former defect area (b), which is covered by an irregular cartilaginous repair tissue (d) protruding into the patellofemoral joint. 


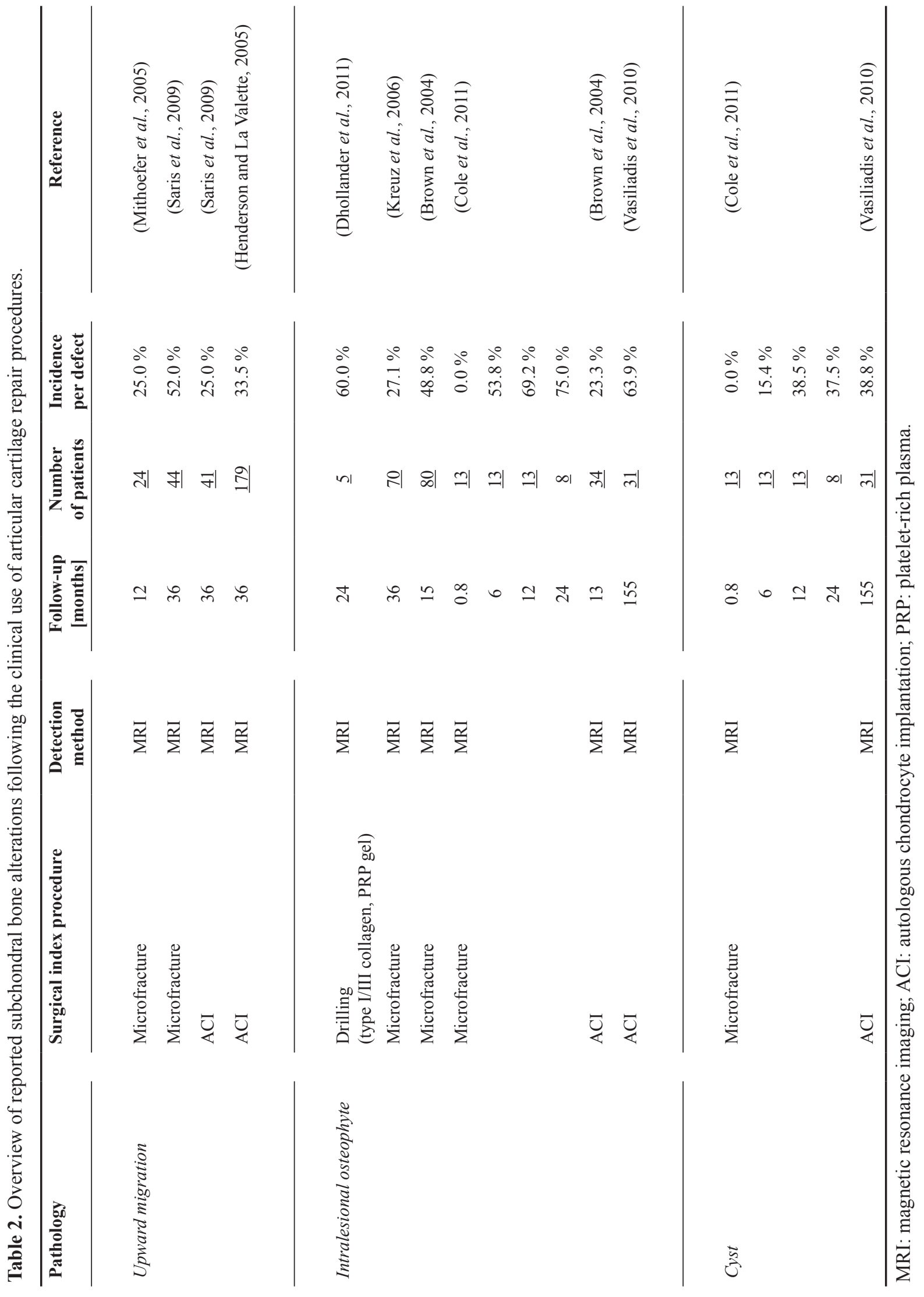


Fig. 6. Arthroscopic view of a large intralesional osteophyte (pointed at by arrowheads) which developed spontaneously without prior surgical treatment within a full-thickness chondral defect in the weightbearing area of the medial femoral condyle in a 43-year-old man. A marking on the calibrated arthroscopic probe (indicated by black triangles) measures $5.0 \mathrm{~mm}$.

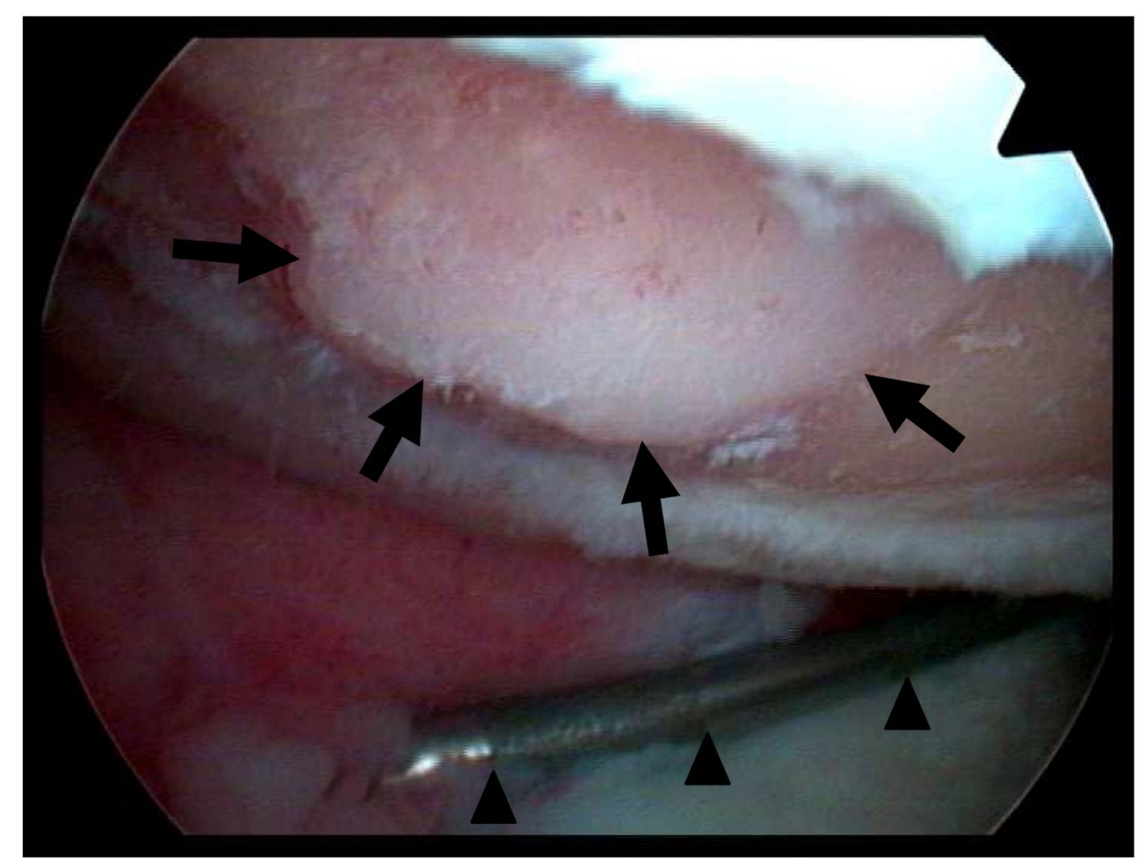

upward migration of the apical border of the subchondral bone plate in $25 \%$ of patients treated with the microfracture technique at a mean follow-up of 41 months (Table 2). Saris et al. (2009) assessed structural MRI outcome parameters 3 years after microfracture using the two-dimensional MOCART score (Marlovits et al., 2004). Defects treated by microfracture developed a progressive elevation of the subchondral bone plate in $52 \%$ of patients.

Generalised elevation of the subchondral bone plate may eventually predispose for the development of osteoarthritis (Potter and Chong, 2009). The cartilaginous repair tissue forms on a comparably thickened, prominent and stiff subchondral bone plate (Simon, 1970), which alters the biomechanical properties of the repair cartilage, such as load distribution throughout the joint (Guettler et al., 2004; Simon, 1970). This may possibly result in an extension of the defect and ultimately osteoarthritic joint degeneration (Minas et al., 2009).

Following ACI, Minas et al. (2009) reported on an upward migration of the subchondral bone plate in $25 \%$ of defects at 3 years postoperatively. In agreement, Henderson and La Valette (2005) described an upward migration of the subchondral bone plate in $34 \%$ of chondral defects as detected by MRI 3 years after ACI (Table 2). Such upward migration was detected in $45 \%$ of defects located at the lateral femoral condyle, in $34 \%$ of defects at the medial femoral condyle, in $29 \%$ of defects located at the trochlea and in $14 \%$ of retropatellar defects. Interestingly, there was a significant association between upward migration of the subchondral bone plate and a larger defect size (mean $3.4 \mathrm{~cm}^{2}$ ) as well as with location at the lateral femoral condyle (Henderson and La Valette, 2005).

\section{Intralesional osteophytes}

Often difficult to distinguish from generalised thickening of the subchondral bone plate, intralesional osteophytes are only seldom described in clinical investigations (Brown et al., 2004; Cole et al., 2009; Dhollander et al., 2011; Kreuz et al., 2006). Cole et al. (2011) did not observe intralesional osteophytes at 3 weeks by MRI assessment, but in $54 \%$ of defects at 6 months, in $69 \%$ at 1 year, and in $75 \%$ at 2 years after microfracture (Table 2). Kreuz et al. (2006) reported on the formation of intralesional osteophytes in $27 \%$ of patients 3 years after microfracture, as detected by MRI evaluation. A propensity for bony overgrowth, resulting in intralesional osteophytes in $49 \%$ of patients - with concomitant loss of adjacent cartilage, was also observed by Brown et al. (2004) at a mean follow-up period of 15 months after microfracture treatment. Dhollander et al. (2011) treated chondral defects of the patella by subchondral drilling in combination with the transplantation of type I/III collagen membranes and a platelet-rich plasma gel. MRI assessment at 2 years postoperatively revealed intralesional osteophytes in $60 \%$ of patients (Dhollander et al., 2011).

Subsequent to ACI, intralesional osteophytes were also detected by MRI in $23 \%$ of patients 13 months postoperatively (Brown et al., 2004). Remarkably, almost one third $(29 \%)$ of these ACI-treated patients presenting with intralesional osteophytes had undergone a previous marrow stimulation procedure (Brown et al., 2004). At a longer follow-up after ACI (mean 12.9 years), Vasiliadis et al. (2010) found intralesional osteophytes in $64 \%$ of defects. Here again, previous affection of the subchondral bone (prior marrow stimulation procedures; history of osteochondrosis dissecans) was evident for $70 \%$ of intralesional osteophytes.

\section{Subchondral bone cysts}

Following microfracture treatment, Cole et al. (2011) detected subchondral cysts beneath the articular cartilage repair tissue by MRI assessment in $15 \%$ of treated defects at 6 months, in $39 \%$ at 1 year and in $38 \%$ at 2 years (Table 2). Interestingly, no cysts were found at 3 weeks 
postoperatively. These findings suggest that subchondral bone cysts do not occur in the first weeks after articular cartilage resurfacing procedures, but are detectable as early as 6 months postoperatively.

At a long-term follow-up between 9 and 18 years after ACI, subchondral cysts were reported in $39 \%$ of defects (Vasiliadis et al., 2010).

\section{Changes in subchondral bone microarchitecture}

In patients with a history of previous marrow stimulation, several studies have addressed the microscopic structure of the articular cartilage repair tissue by evaluating biopsies taken during second-look arthroscopies (Bae et al., 2006; Gobbi et al., 2005; Gudas et al., 2005; Knutsen et al., 2007; Knutsen et al., 2004; Mainil-Varlet et al., 2010; Saris et al., 2009). However, no investigation has histologically examined the microarchitecture of the subchondral bone so far. An entire osteochondral biopsy would be necessary for this purpose, but for ethical considerations can only infrequently be obtained from repaired defect sites in the clinical setting. In theory, such an osteochondral biopsy may be subjected to non-invasive $\mu \mathrm{CT}$ for subchondral bone analysis prior to histological processing. As the resolution power of up-to-date $\mu \mathrm{CT}$ scanners is below $1.0 \mu \mathrm{m}$ (Orth et al., 2012b), while core biopsies are usually obtained using 8-13 G Jamshidi needles (diameter 1.8$3.3 \mathrm{~mm}$ ) (Wei et al., 2003), the technical prerequisites that would allow for the assessment of subchondral bone microarchitecture in such biopsies are already in place. In contrast, for both ethical and technical reasons, the use of high resolution $\mu \mathrm{CT}$ or MRI scanners for in situ analysis of the subchondral bone is still not realisable in patients.

\section{Relevance of subchondral bone alterations for cartilage repair and joint function}

Regarding the clinical long-term results of marrow stimulation techniques, good to excellent results are reported in 60-80\% of patients (Basad et al., 2010; Knutsen et al., 2004; Knutsen et al., 2007; Kon et al., 2009; Mithoefer et al., 2009; Mithoefer et al., 2005; Steadman et al., 2003; Visna et al., 2004). Clinical improvement is achieved as early as 6 months, with the largest improvement occurring during the first 18-24 months (Kreuz et al., 2006; Mithoefer et al., 2009). Studies investigating the repair tissue by MRI showed a high variability (Hayter and Potter, 2011): The grade of defect filling ranged between 18 and $95 \%$ after microfracture treatment of chondral defects (Bachmann et al., 2004; Brown et al., 2004; Gudas et al., 2005; Mithoefer et al., 2005; Ramappa et al., 2007), despite the good correlation of this parameter with the clinical outcome (Kreuz et al., 2006; Mithoefer et al., 2005). Excellent or good MRI results with regard to the presence of subchondral cysts, thickness of the repair tissue, reconstitution of joint congruency (Gudas et al., 2005) or when applying the MOCART system for evaluation purposes (Von Keudell et al., 2011) were found in 8-57\% of treated defects. Mithoefer et al. (2005) reported on pathological MRI signals within the repair tissue in $96 \%$, subchondral oedema in $71 \%$, and insufficient integration of the repair tissue in $92 \%$ of defects two years after microfracture.
In second-look arthroscopies, following marrow stimulation procedures (Bae et al., 2006; Gill, 2000; Gobbi et al., 2005; Gudas et al., 2005; Knutsen et al., 2004; Knutsen et al., 2007; Mainil-Varlet et al., 2010; Nehrer et al., 1999; Ramappa et al., 2007; Saris et al., 2009; Saw et al. 2011), defects are usually well covered with fibrocartilaginous repair tissue at different follow-up periods (Bae et al., 2006; Gobbi et al., 2005; Ramappa et al., 2007; Saw et al., 2011). However, repaired defects only reach average macroscopic grading scores (Bae et al., 2006; Gudas et al., 2005; Knutsen et al., 2004; Riyami and Rolf, 2009). Describing the quality of the cartilage repair tissue more precisely, Gill (2000) reported on fibrillated surfaces in $16 \%$ and fragmented filling in $18 \%$ of defects treated by microfracture 12 months postoperatively. Compared with ACI, microfracture resulted in significantly lower concentrations of type II collagen and proteoglycan in the repair cartilage (Saris et al., 2009). In 1999, Nehrer, Spector and Minas analysed the composition of the reparative tissue from full thickness chondral defects retrieved during revision surgery in 12 patients with failed abrasion arthroplasty. Here, the histological appearance was that of fibrous, spongiform tissue comprising type I collagen in $22 \%$ of the histological cross sectional area, degenerating hyaline tissue in $30 \%$ and fibrocartilage with positive type II collagen staining in $28 \%$ (Nehrer et al., 1999). In good agreement, the repair tissue of patients with failed microfracture or subchondral drilling was fibrocartilaginous and hypercellular 4-19 months after marrow stimulation (Kaul et al., 2012). Interestingly, the subchondral bone beneath this repair tissue was incompletely restored and a new tidemark was absent (Kaul et al., 2012), indicating the lack of a complete regeneration of the osteochondral unit. However, these structural changes still need to be correlated to the clinical outcome of patients in further investigations.

Compared with marrow stimulation procedures, changes to the subchondral bone are less frequently reported following ACI in clinical investigations (Brown et al., 2004; Henderson and La Valette, 2005; Saris et al., 2009; Vasiliadis et al., 2010). Although Saris et al. (2009) and Henderson and La Valette (2005) reported on a lower incidence of subchondral bone plate upward migration following ACI (25 and $34 \%$, respectively; Table 2) compared with microfracture (52\%) at 3 years postoperatively, Vasialiadis et al. (2010) found similar high incidences of intralesional osteophytes and subchondral bone cysts following ACI up to 18 years postoperatively. This suggests that the reported changes in the subchondral bone are comparable between these two different therapeutic strategies in patients.

\section{Possible aetiopathologies of subchondral bone alterations}

No hypothesis has yet been provided to explain the pathological changes in the subchondral bone. Possible aetiopathologies, alone or in synergism, include, but may not be limited to, impaired bone and articular cartilage regeneration processes, pathological structural 
consequences of altered biomechanical loading, disturbed mechanisms of articular cartilage-subchondral bone crosstalk, and pathological vascularisation or angiogenesis.

For example, exposure or perforation of the subchondral bone plate may start the process of bone regeneration, which may extend into the region where the articular cartilage is supposed to be. Similar to the physiological process of endochondral bone formation, bone marrow-derived mesenchymal stem cells (MSCs) and/or chondrocytes may undergo hypertrophy in the deeper regions of the repair tissue, and are then replaced by bone, leading to the pathological formation of osseous tissue within the cartilaginous compartment (Studer et al., 2012). This theory is supported by the presence of type I and type $\mathrm{X}$ collagen in the cartilaginous repair tissue (Kaul et al., 2012). Many factors, among which parathyroid hormone (PTH [1-34]) (Orth et al., 2013a), Sox9 (Cucchiarini et al., 2013), enamel matrix derivative (Kiss et al., 2012), bone morphogenetic proteins and their inhibitors (Rosen, 2006; Ruschke et al., 2012), IGF-I (Kim et al., 2013; Madry et al., 2005), or TGF- $\beta$ (Li et al., 2013; Re'em et al., 2012; Serra et al., 1997), have either been shown or suggested to affect structural patterns of subchondral bone repair in animal models of osteochondral defects in vivo. An imbalance between them may impair the regulation of osteochondral repair. Such deterioration in the crosstalk between cartilage and bone during osteochondral repair (Funck-Brentano and Cohen-Solal, 2011) may additionally be ascribed to hypoxia (Studer et al., 2012) or altered signalling pathways, potentially involving for example the hedgehog family (Rockel and Alman, 2011), the PTH-receptor (Orth et al. 2013a), Wingless/Int (Wnt) (Blom et al., 2010), interleukins (Greenfield et al., 1996), the receptor activator of NF-kappa B ligand (RANKL) (Kwan Tat et al., 2008), or osteoprotegerin (Palmqvist et al., 2002). In addition, vascularisation and angiogenesis may play a role in this process (Gerber and Ferrara, 2000), with different angiogenic (and anti-angiogenic) factors such as VEGF (Gerber et al., 1999; Joyce et al., 1991) being involved. Interestingly, work of Ernst Hunziker showed that obstruction of blood vessel upgrowth from the subchondral bone into the articular cartilage repair tissue significantly reduced subchondral bone plate advancement (Hunziker and Driesang, 2003; Hunziker et al., 2001).

Furthermore, since the quality of the cartilaginous repair tissue is persistently inferior to normal and therefore cannot redistribute load as effectively as normal articular cartilage, biomechanical stresses imposed on the subchondral bone are consecutively increased (Chen et al., 2011a; Qiu et al., 2003). As bone remodels in response to the increased load (Yokota et al., 2011), this response may be inappropriate, inducing either subchondral bone plate migration and intralesional osteophytes, e.g. by metaplasia of the deep layer of the articular cartilage (Shapiro et al., 1993), or impairment of the subchondral bone microarchitecture and the appearance of subchondral bone cysts (Gomoll et al., 2010b; Vasara et al., 2004).

Interestingly, recent work has failed so far to reveal correlations between articular cartilage and subchondral bone repair (Orth et al., 2012a; Orth et al., 2013a), suggesting that both tissues may repair independently.

\section{Conclusion}

Structural alterations of the subchondral bone are associated with spontaneous osteochondral repair and articular cartilage repair procedures in both translational animal models and patients. Experimental data confirm a relevant upward migration of the perforated subchondral bone plate over time. In these models, articular cartilage repair and subchondral bone reconstitution proceed at a different pace, as indicated by the lack of a significant correlation among them (Orth et al., 2012a; Orth et al., 2013a). The subchondral bone plate surrounding treated defects thickened following subchondral drilling (Marchand et al., 2012), suggesting that marrow stimulation may also induce long-term changes in the adjacent subchondral bone.

Clinical investigations show that marrow stimulation techniques exhibit promising clinical results, especially within the first 2 years. According to the experimental findings, marrow stimulation has been associated with the upward migration of the subchondral bone plate, intralesional osteophytes, or bone cysts in a large number of patients. It may be speculated whether these changes play a role in the degeneration and failure of the repair tissue. In good agreement, alterations of the subchondral bone have also been described following ACI, albeit less frequently reported. Here, their incidence is comparable to marrow stimulation techniques, suggesting that none of these different therapeutic approaches is superior with regard to subchondral bone pathologies. Strategies to diminish these subchondral bone alterations are needed, e.g. by optimising different perforation or debridement techniques or postoperative rehabilitation regimes (Anderson and Smith, 2009).

The frequently observed subchondral bone cysts following marrow stimulation are often unrelated to symptoms in patients. Yet, their clinical relevance still needs to be evaluated in more detail (Cox et al., 2011). Regarding the radiographic analysis of the repair process, $\mu \mathrm{CT}$ revealed that marrow stimulation procedures deteriorate the microarchitecture of the entire osteochondral unit for an extended postoperative period. It remains to be elucidated whether pharmacological therapies aimed at counterbalancing these induced pathological changes of the subchondral bone may improve the clinical outcome of marrow stimulation techniques.

Altogether, these emerging experimental and clinical data suggest that a deterioration of the underlying subchondral bone plate and subarticular spongiosa might be an additional, previously underestimated factor that influences the long-term outcome of cartilage repair strategies. These findings are highly relevant for translational cartilage repair models employing cell- or biomaterial-based approaches, since osteochondral repair not only affects the articular cartilage, but also the subchondral bone. A deeper comprehension of the complex role of the subchondral bone in both experimental and clinical articular cartilage repair holds great promise of being translated into further improved cell- or biomaterialbased techniques to preserve and restore the entire osteochondral unit. 


\section{Acknowledgements}

Supported in part by the Gesellschaft für OrthopädischTraumatologische Sportmedizin (GOTS), the Alwin Jäger Stiftung (AJS), the Deutsche Arthrose-Hilfe e.V., and the Gesellschaft für Arthroskopie und Gelenkchirurgie (AGA). We wish to confirm that there are no known conflicts of interest associated with this publication and there has been no significant financial support for this work that could have influenced its outcome.

\section{References}

Anderson AF, Smith M (2009) Progress in cartilage restoration. Am J Sports Med 37 Suppl 1: 7S-9S.

Aroen A, Heir S, Loken S, Engebretsen L, Reinholt FP (2006) Healing of articular cartilage defects. An experimental study of vascular and minimal vascular microenvironment. J Orthop Res 24: 1069-1077.

Bachmann G, Basad E, Lommel D, Steinmeyer J (2004) [MRI in the follow-up of matrix-supported autologous chondrocyte transplantation (MACI) and microfracture]. Radiologe 44: 773-782.

Bae DK, Yoon KH, Song SJ (2006) Cartilage healing after microfracture in osteoarthritic knees. Arthroscopy 22: 367-374.

Basad E, Ishaque B, Bachmann G, Sturz H, Steinmeyer J (2010) Matrix-induced autologous chondrocyte implantation versus microfracture in the treatment of cartilage defects of the knee: a 2-year randomised study. Knee Surg Sports Traumatol Arthrosc 18: 519-524.

Batty L, Dance S, Bajaj S, Cole BJ (2011) Autologous chondrocyte implantation: an overview of technique and outcomes. ANZ J Surg 81: 18-25.

Blom AB, van Lent PL, van der Kraan PM, van den Berg WB (2010) To seek shelter from the WNT in osteoarthritis? WNT-signaling as a target for osteoarthritis therapy. Curr Drug Targets 11: 620-629.

Brittberg M, Lindahl A, Nilsson A, Ohlsson C, Isaksson O, Peterson L (1994) Treatment of deep cartilage defects in the knee with autologous chondrocyte transplantation. N Engl J Med 331: 889-895.

Broom ND, Poole CA (1982) A functionalmorphological study of the tidemark region of articular cartilage maintained in a non-viable physiological condition. J Anat 135: 65-82.

Brown WE, Potter HG, Marx RG, Wickiewicz TL, Warren RF (2004) Magnetic resonance imaging appearance of cartilage repair in the knee. Clin Orthop Relat Res 422: 214-223.

Bullough PG, Jagannath A (1983) The morphology of the calcification front in articular cartilage. Its significance in joint function. J Bone Joint Surg Br 65: 72-78.

Burr DB (2004) The importance of subchondral bone in the progression of osteoarthritis. J Rheumatol Suppl 70: 77-80.

Chen H, Sun J, Hoemann CD, Lascau-Coman V, Ouyang W, McKee MD, Shive MS, Buschmann MD (2009) Drilling and microfracture lead to different bone structure and necrosis during bone-marrow stimulation for cartilage repair. J Orthop Res 27: 1432-1438.

Chen H, Chevrier A, Hoemann CD, Sun J, Ouyang W, Buschmann MD (2011a) Characterization of subchondral bone repair for marrow-stimulated chondral defects and its relationship to articular cartilage resurfacing. Am J Sports Med 39: 1731-1740.

Chen H, Hoemann CD, Sun J, Chevrier A, McKee MD, Shive MS, Hurtig M, Buschmann MD (2011b) Depth of subchondral perforation influences the outcome of bone marrow stimulation cartilage repair. J Orthop Res 29: 1178-1184.

Chevrier A, Hoemann CD, Sun J, Buschmann MD (2007) Chitosan-glycerol phosphate/blood implants increase cell recruitment, transient vascularization and subchondral bone remodeling in drilled cartilage defects. Osteoarthritis Cartilage 15: 316-327.

Cole BJ, Pascual-Garrido C, Grumet RC (2009) Surgical management of articular cartilage defects in the knee. J Bone Joint Surg Am 91: 1778-1790.

Cole BJ, Farr J, Winalski CS, Hosea T, Richmond J, Mandelbaum B, De Deyne PG (2011) Outcomes after a single-stage procedure for cell-based cartilage repair: a prospective clinical safety trial with 2-year follow-up. Am J Sports Med 39: 1170-1179.

Cox LG, Lagemaat MW, van Donkelaar CC, van Rietbergen B, Reilingh ML, Blankevoort L, van Dijk CN, Ito $\mathrm{K}$ (2011) The role of pressurized fluid in subchondral bone cyst growth. Bone 49: 762-768.

Cucchiarini M, Orth P, Madry H (2013) Direct rAAV Sox9 administration for durable articular cartilage repair with delayed terminal differentiation and hypertrophy in vivo. J Mol Med (Berl) 91: 625-36.

Dell'Accio F, Vanlauwe J, Bellemans J, Neys J, De Bari C, Luyten FP (2003) Expanded phenotypically stable chondrocytes persist in the repair tissue and contribute to cartilage matrix formation and structural integration in a goat model of autologous chondrocyte implantation. J Orthop Res 21: 123-131.

Dhollander AA, De Neve F, Almqvist KF, Verdonk R, Lambrecht S, Elewaut D, Verbruggen G, Verdonk PC (2011) Autologous matrix-induced chondrogenesis combined with platelet-rich plasma gel: technical description and a five pilot patients report. Knee Surg Sports Traumatol Arthrosc 19: 536-542.

Dorotka R, Bindreiter U, Macfelda K, Windberger U, Nehrer S (2005) Marrow stimulation and chondrocyte transplantation using a collagen matrix for cartilage repair. Osteoarthritis Cartilage 13: 655-664.

Drobnic M, Radosavljevic D, Cor A, Brittberg M, Strazar K (2010) Debridement of cartilage lesions before autologous chondrocyte implantation by open or transarthroscopic techniques: a comparative study using post-mortem materials. J Bone Joint Surg Br 92: 602-608.

Feldkamp LA, Goldstein SA, Parfitt AM, Jesion G, Kleerekoper M (1989) The direct examination of threedimensional bone architecture in vitro by computed tomography. J Bone Miner Res 4: 3-11.

Fortier LA, Cole BJ, McIlwraith CW (2012) Science and animal models of marrow stimulation for cartilage repair. J Knee Surg 25: 3-8. 
Frisbie DD, Trotter GW, Powers BE, Rodkey WG, Steadman JR, Howard RD, Park RD, McIlwraith CW (1999) Arthroscopic subchondral bone plate microfracture technique augments healing of large chondral defects in the radial carpal bone and medial femoral condyle of horses. Vet Surg 28: 242-255.

Frisbie DD, Morisset S, Ho CP, Rodkey WG, Steadman JR, McIlwraith CW (2006) Effects of calcified cartilage on healing of chondral defects treated with microfracture in horses. Am J Sports Med 34: 1824-1831.

Funck-Brentano T, Cohen-Solal M (2011) Crosstalk between cartilage and bone: when bone cytokines matter. Cytokine Growth Factor Rev 22: 91-97.

Furukawa T, Eyre DR, Koide S, Glimcher MJ (1980) Biochemical studies on repair cartilage resurfacing experimental defects in the rabbit knee. J Bone Joint Surg Am 62: 79-89.

Gerber HP, Ferrara N (2000) Angiogenesis and bone growth. Trends Cardiovasc Med 10: 223-228.

Gerber HP, Vu TH, Ryan AM, Kowalski J, Werb Z, Ferrara N (1999) VEGF couples hypertrophic cartilage remodeling, ossification and angiogenesis during endochondral bone formation. Nat Med 5: 623-628.

Gill TJ (2000) The treatment of articular cartilage defects using microfracture and debridement. Am J Knee Surg 13: 33-40.

Gobbi A, Nunag P, Malinowski K (2005) Treatment of full thickness chondral lesions of the knee with microfracture in a group of athletes. Knee Surg Sports Traumatol Arthrosc 13: 213-221.

Goebel L, Orth P, Muller A, Zurakowski D, Bucker A, Cucchiarini M, Pape D, Madry H (2012) Experimental scoring systems for macroscopic articular cartilage repair correlate with the MOCART score assessed by a highfield MRI at 9.4 Tesla - comparative evaluation of five macroscopic scoring systems in a large animal cartilage defect model. Osteoarthritis Cartilage 20: 1046-1055.

Gomoll AH, Farr J, Gillogly SD, Kercher J, Minas T (2010a) Surgical management of articular cartilage defects of the knee. J Bone Joint Surg Am 92: 2470-2490.

Gomoll AH, Madry H, Knutsen G, van Dijk N, Seil R, Brittberg M, Kon E (2010b) The subchondral bone in articular cartilage repair: current problems in the surgical management. Knee Surg Sports Traumatol Arthrosc 18: 434-447.

Grana WA (2000) Healing of articular cartilage: a review. Am J Knee Surg 13: 29-32.

Green WT, Jr., Martin GN, Eanes ED, Sokoloff L (1970) Microradiographic study of the calcified layer of articular cartilage. Arch Pathol 90: 151-158.

Greenfield EM, Horowitz MC, Lavish SA (1996) Stimulation by parathyroid hormone of interleukin- 6 and leukemia inhibitory factor expression in osteoblasts is an immediate-early gene response induced by cAMP signal transduction. J Biol Chem 271: 10984-10989.

Gudas R, Kalesinskas RJ, Kimtys V, Stankevicius E, Toliusis V, Bernotavicius G, Smailys A(2005) A prospective randomized clinical study of mosaic osteochondral autologous transplantation versus microfracture for the treatment of osteochondral defects in the knee joint in young athletes. Arthroscopy 21: 1066-1075.
Guettler JH, Demetropoulos CK, Yang KH, Jurist KA (2004) Osteochondral defects in the human knee: influence of defect size on cartilage rim stress and load redistribution to surrounding cartilage. Am J Sports Med 32: 1451-1458.

Hanie EA, Sullins KE, Powers BE, Nelson PR (1992) Healing of full-thickness cartilage compared with fullthickness cartilage and subchondral bone defects in the equine third carpal bone. Equine Vet J 24: 382-386.

Hayter C, Potter H (2011) Magnetic resonance imaging of cartilage repair techniques. J Knee Surg 24: 225-240.

Heir S, Aroen A, Loken S, Holme I, Engebretsen L, Reinholt FP (2012) Cartilage repair in the rabbit knee: mosaic plasty resulted in higher degree of tissue filling but affected subchondral bone more than microfracture technique: A blinded, randomized, controlled, long-term follow-up trial in 88 knees. Knee Surg Sports Traumatol Arthrosc 20: 197-209.

Henderson IJ, La Valette DP (2005) Subchondral bone overgrowth in the presence of full-thickness cartilage defects in the knee. Knee 12: 435-440.

Henrotin Y, Pesesse L, Sanchez C (2009) Subchondral bone in osteoarthritis physiopathology: state-of-the art and perspectives. Biomed Mater Eng 19: 311-316.

Hoemann CD, Hurtig M, Rossomacha E, Sun J, Chevrier A, Shive MS, Buschmann MD (2005) Chitosanglycerol phosphate/blood implants improve hyaline cartilage repair in ovine microfracture defects. J Bone Joint Surg Am 87: 2671-2686.

Howard RD, McIlwraith CW, Trotter GW, Powers BE, McFadden PR, Harwood FL, Amiel D (1994) Long-term fate and effects of exercise on sternal cartilage autografts used for repair of large osteochondral defects in horses. Am J Vet Res 55: 1158-1167.

Hunziker EB, Driesang IM (2003) Functional barrier principle for growth-factor-based articular cartilage repair. Osteoarthritis Cartilage 11: 320-327.

Hunziker EB, Driesang IM, Saager C (2001) Structural barrier principle for growth factor-based articular cartilage repair. Clin Orthop Relat Res 391 Suppl: S182189. Hunziker EB, Quinn TM, Hauselmann HJ (2002) Quantitative structural organization of normal adult human articular cartilage. Osteoarthritis Cartilage 10: 564-572.

Hurtig M, Pearce S, Warren S, Kalra M, Miniaci A (2001) Arthroscopic mosaic arthroplasty in the equine third carpal bone. Vet Surg 30: 228-239.

Ishimaru JI, Kurita K, Handa Y, Goss AN (1992) Effect of marrow perforation on the sheep temporomandibular joint. Int J Oral Maxillofac Surg 21: 239-242.

Jackson DW, Lalor PA, Aberman HM, Simon TM (2001) Spontaneous repair of full-thickness defects of articular cartilage in a goat model. A preliminary study. $\mathrm{J}$ Bone Joint Surg Am 83A: 53-64.

Jeffery AK (1973) Osteogenesis in the osteoarthritic femoral head. A study using radioactive $32 \mathrm{P}$ and tetracycline bone markers. J Bone Joint Surg Br 55: 262-272.

Johnson LL (1986) Arthroscopic abrasion arthroplasty historical and pathologic perspective: present status. Arthroscopy 2: 54-69.

Johnson LL (2001) Arthroscopic abrasion arthroplasty: a review. Clin Orthop Relat Res 391 Suppl: S306-317. 
Joyce ME, Jingushi S, Scully SP, Bolander ME (1991) Role of growth factors in fracture healing. Prog Clin Biol Res 365: 391-416.

Kaul G, Cucchiarini M, Remberger K, Kohn D, Madry H (2012) Failed cartilage repair for early osteoarthritis defects: a biochemical, histological and immunohistochemical analysis of the repair tissue after treatment with marrow-stimulation techniques. Knee Surg Sports Traumatol Arthrosc 20: 2315-2324.

Kim K, Lam J, Lu S, Spicer PP, Lueckgen A, Tabata Y, Wong ME, Jansen JA, Mikos AG, Kasper FK (2013) Osteochondral tissue regeneration using a bilayered composite hydrogel with modulating dual growth factor release kinetics in a rabbit model. J Control Release 168: 166-178.

Kiss A, Cucchiarini M, Menger MD, Kohn D, Hannig M, Madry H (2012) Enamel matrix derivative inhibits proteoglycan production and articular cartilage repair, delays the restoration of the subchondral bone and induces changes of the synovial membrane in a lapine osteochondral defect model in vivo. J Tissue Eng Regen Med: doi: 10.1002/term.1495.

Knutsen G, Engebretsen L, Ludvigsen TC, Drogset JO, Grontvedt T, Solheim E, Strand T, Roberts S, Isaksen V, Johansen O (2004) Autologous chondrocyte implantation compared with microfracture in the knee. A randomized trial. J Bone Joint Surg Am 86A: 455-464.

Knutsen G, Drogset JO, Engebretsen L, Grontvedt T, Isaksen V, Ludvigsen TC, Roberts S, Solheim E, Strand $\mathrm{T}$, Johansen O (2007) A randomized trial comparing autologous chondrocyte implantation with microfracture. Findings at five years. J Bone Joint Surg 89A: 2105-2112.

Kon E, Gobbi A, Filardo G, Delcogliano M, Zaffagnini S, Marcacci M (2009) Arthroscopic second-generation autologous chondrocyte implantation compared with microfracture for chondral lesions of the knee: prospective nonrandomized study at 5 years. Am J Sports Med 37: 33 41.

Kreuz PC, Steinwachs MR, Erggelet C, Krause SJ, Konrad G, Uhl M, Südkamp N (2006) Results after microfracture of full-thickness chondral defects in different compartments in the knee. Osteoarthritis Cartilage 14: 1119-1125.

Kwan Tat S, Pelletier JP, Lajeunesse D, Fahmi H, Lavigne M, Martel-Pelletier J (2008) The differential expression of osteoprotegerin (OPG) and receptor activator of nuclear factor kappaB ligand (RANKL) in human osteoarthritic subchondral bone osteoblasts is an indicator of the metabolic state of these disease cells. Clin Exp Rheumatol 26: 295-304.

Lajeunesse D, Hilal G, Pelletier JP, Martel-Pelletier J (1999) Subchondral bone morphological and biochemical alterations in osteoarthritis. Osteoarthritis Cartilage 7: 321322.

Lane JG, Massie JB, Ball ST, Amiel ME, Chen AC, Bae WC, Sah RL, Amiel D (2004) Follow-up of osteochondral plug transfers in a goat model: a 6-month study. Am J Sports Med 32: 1440-1450.

Li B, Yang J, Ma L, Li F, Tu Z, Gao C (2013) Fabrication of poly(lactide-co-glycolide) scaffold filled with fibrin gel, mesenchymal stem cells, and poly(ethylene oxide)-b-
poly(L-lysine)/TGF-beta1 plasmid DNA complexes for cartilage restoration in vivo. J Biomed Mater Res A doi: 10.1002/jbm.a.34618.

Madry H (2010) The subchondral bone: a new frontier in articular cartilage repair. Knee Surg Sports Traumatol Arthrosc 18: 417-418.

Madry H, Kaul G, Cucchiarini M, Stein U, Zurakowski D, Remberger K, Menger MD, Kohn D, Trippel SB (2005) Enhanced repair of articular cartilage defects in vivo by transplanted chondrocytes overexpressing insulin-like growth factor I (IGF-I). Gene Ther 12: 1171-1179.

Madry H, van Dijk CN, Mueller-Gerbl M (2010) The basic science of the subchondral bone. Knee Surg Sports Traumatol Arthrosc 18: 419-433.

Mainil-Varlet P, Van Damme B, Nesic D, Knutsen G, Kandel R, Roberts S (2010) A new histology scoring system for the assessment of the quality of human cartilage repair: ICRS II. Am J Sports Med 38: 880-890.

Marchand C, Chen H, Buschmann MD, Hoemann CD (2011) Standardized three-dimensional volumes of interest with adapted surfaces for more precise subchondral bone analyses by micro-computed tomography. Tissue Eng Part C Methods 17: 475-484.

Marchand C, Chen G, Tran-Khanh N, Sun J, Chen H, Buschmann MD, Hoemann CD (2012) Microdrilled cartilage defects treated with thrombin-solidified chitosan/ blood implant regenerate a more hyaline, stable, and structurally integrated osteochondral unit compared to drilled controls. Tissue Eng Part A 18: 508-519.

Marlovits S, Striessnig G, Resinger CT, Aldrian SM, Vecsei V, Imhof H, Trattnig S (2004) Definition of pertinent parameters for the evaluation of articular cartilage repair tissue with high-resolution magnetic resonance imaging. Eur J Radiol 52: 310-319.

Mastbergen SC, Pollmeier M, Fischer L, Vianen ME, Lafeber FP (2008) The groove model of osteoarthritis applied to the ovine fetlock joint. Osteoarthritis Cartilage 16: 919-928.

Menetrey J, Unno-Veith F, Madry H, Van Breuseghem I (2010) Epidemiology and imaging of the subchondral bone in articular cartilage repair. Knee Surg Sports Traumatol Arthrosc 18: 463-471.

Minas T, Gomoll AH, Rosenberger R, Royce RO, Bryant T (2009) Increased failure rate of autologous chondrocyte implantation after previous treatment with marrow stimulation techniques. Am J Sports Med 37: 902-908.

Mithoefer K, Williams RJ, 3rd, Warren RF, Potter HG, Spock CR, Jones EC, Wickiewicz TL, Marx RG (2005) The microfracture technique for the treatment of articular cartilage lesions in the knee. A prospective cohort study. J Bone Joint Surg Am 87: 1911-1920.

Mithoefer K, McAdams T, Williams RJ, Kreuz PC, Mandelbaum BR (2009) Clinical efficacy of the microfracture technique for articular cartilage repair in the knee: an evidence-based systematic analysis. Am J Sports Med 37: 2053-2063.

Moran CJ, Barry FP, Maher SA, Shannon FJ, Rodeo SA (2012) Advancing regenerative surgery in orthopaedic sports medicine: the critical role of the surgeon. Am J Sports Med 40: 934-944. 
Nam EK, Makhsous M, Koh J, Bowen M, Nuber G, Zhang LQ (2004) Biomechanical and histological evaluation of osteochondral transplantation in a rabbit model. Am J Sports Med 32: 308-316.

Nehrer S, Spector M, Minas T (1999) Histologic analysis of tissue after failed cartilage repair procedures. Clin Orthop Relat Res 365: 149-162.

Orth P, Cucchiarini M, Kaul G, Ong MF, Graber S, Kohn DM, Madry H (2012a) Temporal and spatial migration pattern of the subchondral bone plate in a rabbit osteochondral defect model. Osteoarthritis Cartilage 20: 1161-1169.

Orth P, Goebel L, Wolfram U, Ong MF, Graber S, Kohn D, Cucchiarini M, Ignatius A, Pape D, Madry H (2012b) Effect of subchondral drilling on the microarchitecture of subchondral bone: analysis in a large animal model at 6 months. Am J Sports Med 40: 828-836.

Orth P, Cucchiarini M, Zurakowski D, Menger MD, Kohn DM, Madry H (2013a) Parathyroid hormone [134] improves articular cartilage surface architecture and integration and subchondral bone reconstitution in osteochondral defects in vivo. Osteoarthritis Cartilage 21: 614-624.

Palmqvist P, Persson E, Conaway HH, Lerner UH (2002) IL-6, leukemia inhibitory factor, and oncostatin M stimulate bone resorption and regulate the expression of receptor activator of NF-kappa B ligand, osteoprotegerin, and receptor activator of NF-kappa B in mouse calvariae. J Immunol 169: 3353-3362.

Pape D, Filardo G, Kon E, van Dijk CN, Madry H (2010) Disease-specific clinical problems associated with the subchondral bone. Knee Surg Sports Traumatol Arthrosc 18: 448-462.

Parfitt AM, Drezner MK, Glorieux FH, Kanis JA, Malluche H, Meunier PJ, Ott SM, Recker RR (1987) Bone histomorphometry: standardization of nomenclature, symbols, and units. Report of the ASBMR Histomorphometry Nomenclature Committee. J Bone Miner Res 2: 595-610.

Pearce SG, Hurtig MB, Clarnette R, Kalra M, Cowan B, Miniaci A (2001) An investigation of 2 techniques for optimizing joint surface congruency using multiple cylindrical osteochondral autografts. Arthroscopy 17: 5055.

Potter HG, Chong le R (2009) Magnetic resonance imaging assessment of chondral lesions and repair. J Bone Joint Surg Am 91 Suppl 1: 126-131.

Pridie KH (1959) A method of resurfacing knee joints. J Bone Joint Surg Br 41: 618.

Pritzker KP, Gay S, Jimenez SA, Ostergaard K, Pelletier JP, Revell PA, Salter D, van den Berg WB (2006) Osteoarthritis cartilage histopathology: grading and staging. Osteoarthritis Cartilage 14: 13-29.

Qiu YS, Shahgaldi BF, Revell WJ, Heatley FW (2003) Observations of subchondral plate advancement during osteochondral repair: a histomorphometric and mechanical study in the rabbit femoral condyle. Osteoarthritis Cartilage 11: 810-820.

Radin EL, Burr DB, Caterson B, Fyhrie D, Brown TD, Boyd RD (1991) Mechanical determinants of osteoarthrosis. Semin Arthritis Rheum 21: 12-21.
Ramappa AJ, Gill TJ, Bradford CH, Ho CP, Steadman JR (2007) Magnetic resonance imaging to assess knee cartilage repair tissue after microfracture of chondral defects. J Knee Surg 20: 228-234.

Re'em T, Witte F, Willbold E, Ruvinov E, Cohen S (2012) Simultaneous regeneration of articular cartilage and subchondral bone induced by spatially presented TGFbeta and BMP-4 in a bilayer affinity binding system. Acta Biomater 8: 3283-3293.

Riyami M, Rolf C (2009) Evaluation of microfracture of traumatic chondral injuries to the knee in professional football and rugby players. J Orthop Surg Res 4: 13.

Rockel JS, Alman BA (2011) Don't hedge your bets: hedgehog signaling as a central mediator of endochondral bone development and cartilage diseases. J Orthop Res 29: 810-815.

Rosen V (2006) BMP and BMP inhibitors in bone. Ann N Y Acad Sci 1068: 19-25.

Ruschke K, Hiepen C, Becker J, Knaus P (2012) BMPs are mediators in tissue crosstalk of the regenerating musculoskeletal system. Cell Tissue Res 347: 521-544.

Safran MR, Seiber K (2010) The evidence for surgical repair of articular cartilage in the knee. J Am Acad Orthop Surg 18: 259-266.

Saris DB, Vanlauwe J, Victor J, Almqvist KF, Verdonk R, Bellemans J, Luyten FP (2009) Treatment of symptomatic cartilage defects of the knee: characterized chondrocyte implantation results in better clinical outcome at 36 months in a randomized trial compared to microfracture. Am J Sports Med 37 Suppl 1: 10S-19S.

Saw KY, Anz A, Merican S, Tay YG, Ragavanaidu K, Jee CS, McGuire DA (2011) Articular cartilage regeneration with autologous peripheral blood progenitor cells and hyaluronic acid after arthroscopic subchondral drilling: a report of 5 cases with histology. Arthroscopy 27: 493-506.

Serra R, Johnson M, Filvaroff EH, LaBorde J, Sheehan DM, Derynck R, Moses HL (1997) Expression of a truncated, kinase-defective TGF-beta type II receptor in mouse skeletal tissue promotes terminal chondrocyte differentiation and osteoarthritis. J Cell Biol 139: 541-552.

Shahgaldi BF, Amis AA, Heatley FW, McDowell J, Bentley G (1991) Repair of cartilage lesions using biological implants. A comparative histological and biomechanical study in goats. J Bone Joint Surg $\mathrm{Br}$ 73: 57-64.

Shamis LD, Bramlage LR, Gabel AA, Weisbrode S (1989) Effect of subchondral drilling on repair of partialthickness cartilage defects of third carpal bones in horses. Am J Vet Res 50: 290-295.

Shapiro F, Koide S, Glimcher MJ (1993) Cell origin and differentiation in the repair of full-thickness defects of articular cartilage. J Bone Joint Surg Am 75: 532-553.

Simon WH (1970) Scale effects in animal joints. I. Articular cartilage thickness and compressive stress. Arthritis Rheum 13: 244-256.

Siu WS, Qin L, Cheung WH, Leung KS (2004) A study of trabecular bones in ovariectomized goats with micro-computed tomography and peripheral quantitative computed tomography. Bone 35: 21-26. 
Sniekers YH, Intema F, Lafeber FP, van Osch GJ, van Leeuwen JP, Weinans H, Mastbergen SC (2008) A role for subchondral bone changes in the process of osteoarthritis; a micro-CT study of two canine models. BMC Musculoskelet Disord 9: 20-31.

Steadman JR, Rodkey WG, Rodrigo JJ (2001) Microfracture: surgical technique and rehabilitation to treat chondral defects. Clin Orthop Relat Res 391 Suppl: S362-369.

Steadman JR, Briggs KK, Rodrigo JJ, Kocher MS, Gill TJ, Rodkey WG (2003) Outcomes of microfracture for traumatic chondral defects of the knee: average 11-year follow-up. Arthroscopy 19: 477-484.

Studer D, Millan C, Ozturk E, Maniura-Weber K, Zenobi-Wong M (2012) Molecular and biophysical mechanisms regulating hypertrophic differentiation in chondrocytes and mesenchymal stem cells. Eur Cell Mater 24: 118-135.

Tetteh ES, Bajaj S, Ghodadra NS (2012) Basic science and surgical treatment options for articular cartilage injuries of the knee. J Orthop Sports Phys Ther 42: 243253.

Vachon A, Bramlage LR, Gabel AA, Weisbrode S (1986) Evaluation of the repair process of cartilage defects of the equine third carpal bone with and without subchondral bone perforation. Am J Vet Res 47: $2637-$ 2645.

van der Kraan PM, van den Berg WB (2007) Osteophytes: relevance and biology. Osteoarthritis Cartilage 15: 237-244.

Vasara AI, Hyttinen MM, Lammi MJ, Lammi PE, Langsjo TK, Lindahl A, Peterson L, Kellomaki M, Konttinen YT, Helminen HJ, Kiviranta I (2004) Subchondral bone reaction associated with chondral defect and attempted cartilage repair in goats. Calcif Tissue Int 74: 107-114.

Vasiliadis HS, Danielson B, Ljungberg M, McKeon B, Lindahl A, Peterson L (2010) Autologous chondrocyte implantation in cartilage lesions of the knee: Long-term evaluation with magnetic resonance imaging and delayed gadolinium-enhanced magnetic resonance imaging technique. Am J Sports Med 38: 943-949.

Visna P, Pasa L, Cizmar I, Hart R, Hoch J (2004) Treatment of deep cartilage defects of the knee using autologous chondrograft transplantation and by abrasive techniques - a randomized controlled study. Acta Chir Belg 104: 709-714.

Von Keudell A, Atzwanger J, Forstner R, Resch H, Hoffelner T, Mayer M (2011) Radiological evaluation of cartilage after microfracture treatment: A long-term followup study. Eur J Radiol 81: 1618-1624.

von Rechenberg B, Akens MK, Nadler D, Bittmann P, Zlinszky K, Kutter A, Poole AR, Auer JA (2003) Changes in subchondral bone in cartilage resurfacing an experimental study in sheep using different types of osteochondral grafts. Osteoarthritis Cartilage 11: 265-277.

Wei N, Johnson LL, Seely BL, Delauter SK (2003) Arthroscopically guided Jamshidi needle biopsy of articular cartilage: potential utility in the evaluation of disease modifying osteoarthritis drugs (DMOADS). J Appl Res 3(3).
Williams RJ, Brophy RH (2008) Cartilage repair procedures: clinical approach and decision making. Instr Course Lect 57: 553-561.

Wu Q, Kim KO, Sampson ER, Chen D, Awad H, O'Brien T, Puzas JE, Drissi H, Schwarz EM, O'Keefe RJ, Zuscik MJ, Rosier RN (2008) Induction of an osteoarthritislike phenotype and degradation of phosphorylated Smad3 by Smurf2 in transgenic mice. Arthritis Rheum 58: 31323144.

Wei N, Johnson LL, Seely BL, Delauter SK (2003) Yokota H, Leong DJ, Sun HB (2011) Mechanical loading: bone remodeling and cartilage maintenance. Curr Osteoporos Rep 9: 237-242.

\section{Discussion with Reviewers}

Reviewer I: In translational studies, what set of outcome parameters would you recommend to be implemented for assessing the pathological changes in the subchondral bone?

Authors: In translational animal studies, the upward migration of the subchondral bone plate can be assessed by histomorphometrical measurements. Standardised methods to determine the migration of the subchondral bone plate on histological sections have been described (Orth et al., 2012a; Qiu et al., 2003). For the formation of subchondral bone cysts, the group of Hoemann et al. (2005) has established a scoring system to evaluate their formation and severity. With special regard to the formation of subchondral bone cysts following marrow stimulation procedures and their differentiation to lacunae of the subarticular spongiosa, cysts are defined as having a minimum diameter of at least triple the diameter of the perforation instrument (microfracture awl, subchondral bone drill) (Orth et al., 2012b). The incidence of subchondral bone cysts and intralesional osteophytes can be assessed and quantified by both micro-CT and histomorphometry. We have previously categorised intralesional osteophytes as being either central or peripheral, depending whether they are located between subchondral bone perforations (microfracture holes or drill holes) or between perforations and the defect border (Orth et al., 2012b). To assess the impairment of the osseous microarchitecture, micro-CT as well as histomorphometrical evaluation are suitable. In our opinion, the most crucial parameters for both evaluation techniques are bone mineral density (BMD), bone volume fraction $(\mathrm{BV} / \mathrm{TV})$, bone surface/volume ratio $(\mathrm{BS} / \mathrm{BV})$, bone surface density (BS/TV), cortical thickness (Ct.Th), trabecular thickness (Tb.Th), and trabecular separation (Tb. Sp) (Feldkamp et al., 1989; Orth et al., 2013a; Orth et al., 2012b). However, these measures are more difficult to be applied in clinical studies.

Reviewer II: What mechanisms do the authors believe are responsible for the 'upward migrating' of the subchondral bone plate?

Authors: We believe that endochondral ossification is a major mechanism that may be responsible for the upward migration of the subchondral bone plate as well as for the formation of intralesional osteophytes. Similar to 
the physiological process of endochondral ossification of the growth plate (Gerber and Ferrara, 2000; Studer et al., 2012), chondrocytes may undergo hypertrophy in the deeper regions of the repair tissue, and are then replaced by bone, leading to the pathological formation of osseous tissue within the cartilaginous compartment. This theory is supported by the presence of type I and type $\mathrm{X}$ collagen in the cartilaginous repair tissue (Kaul et al., 2012). Vascularisation and angiogenesis play a key role in this process (Gerber and Ferrara, 2000). Furthermore, biomechanical stresses imposed on the subchondral bone within the defect are consecutively increased (Chen et al., 2011; Qiu et al., 2003). As bone remodels in response to the increased load (Yokota et al., 2011), this response may be inappropriate, inducing subchondral bone plate migration.

Reviewer II: What cells are likely to be involved in subchondral bone changes and what are the driving forces? Authors: Cells involved in the formation of intralesional osteophytes or in the upward migration of the subchondral bone plate are most likely osteoblasts from the subchondral bone plate as well as bone-marrow derived stems cells which gain access to the defect (Jackson et al., 2001; Shapiro et al., 1993). Furthermore, cells from the synovial lining may also contribute to the repopulation of the cartilage defects (Hunziker and Rosenberg, 1996). All of these cell populations may differentially express various factors, among which parathyroid hormone (PTH [1-34]) (Orth et al., 2013a), Sox9 (Cucchiarini et al., 2013), enamel matrix derivative (Kiss et al., 2012), bone morphogenetic proteins and their inhibitors (Rosen, 2006; Ruschke et al., 2012), IGF-I (Kim et al., 2013; Madry et al., 2005), or TGF- $\beta$ (Li et al., 2013; Re'em et al., 2012; Serra et al., 1997) have either been shown or suggested to affect structural patterns of subchondral bone repair in animal models of osteochondral defects in vivo. An imbalance between them may impair the regulation of osteochondral repair. Such deterioration in the crosstalk between cartilage and bone during osteochondral repair (Funck-Brentano and Cohen-Solal, 2012) may additionally be ascribed to hypoxia (Studer et al., 2012) or altered signalling pathways, potentially involving for example the hedgehog family (Rockel and Alman, 2011), the PTH-receptor (Orth et al. 2013a), Wingless/Int (Wnt) (Blom et al., 2010), interleukins (Greenfield et al., 1996), the receptor activator of NF-kappa B ligand (RANKL) (Kwan Tat et al., 2008), or osteoprotegerin (Palmqvist et al., 2002). In addition, vascularisation and angiogenesis may play a role in this process (Gerber and Ferrara, 2000), with different angiogenic (and anti-angiogenic) factors such as VEGF (Gerber et al., 1999; Joyce et al., 1991) being involved. Furthermore, biomechanical stresses imposed on the subchondral bone are increased in cartilage lesions (Chen et al., 2011; Qiu et al., 2003). As bone remodels in response to the increased load (Yokota et al., 2011), this response may be inappropriate, possibly inducing subchondral bone plate migration and the formation of intralesional osteophytes.

Reviewer II: Do they have some suggestions for controlling subchondral bone changes in future repair techniques?
Authors: Regarding vascularisation processes as one possible aetiopathology, two interesting approaches to avoid subchondral bone overgrowth have been reported by Ernst Hunziker, the so-called structural barrier principle and the functional barrier principle. The structural barrier principle describes the implantation of a cell and blood vessel-excluding membrane (Millipore ${ }^{\circledR}$ or Goretex ${ }^{\circledR}$ ), inserted at the interface between cartilage and bone compartments within osteochondral defects (Hunziker et al., 2001). The functional barrier principle implies the addition of an anti-angiogenic factor (suramin) to the chondrogenic matrix implanted into chondral defects in order to prevent vascularisation within the cartilaginous compartment (Hunziker and Driesang, 2003). In agreement, Klinger et al. (2011) significantly inhibited terminal chondrocyte hypertrophy, the invasion of vessel structures, and excessive endochondral ossification by overexpression of chondromodulin-1 in cartilage defects in the knee joints of miniature pigs that were treated by microfracture. With regard to the enhanced biomechanical stresses acting on subchondral bone underlying cartilage lesions, it remains to be elucidated whether different postoperative weight-bearing regimes (Anderson and Smith, 2009) may delimit the upward migration of the subchondral bone plate or the formation of intralesional osteophytes. The authors have recently demonstrated that a bone anabolic pharmacological therapy with PTH [1-34] enhances the microarchitectural patterns of the repaired subchondral bone plate as well as of the subarticular spongiosa in a rabbit model of osteochondral defects (Orth et al., 2013a).

Reviewer III: Can the authors give some of their ideas as to why some osteochondral defects (in animal models) give rise to bone plate overgrowth, or subchondral cysts, and others do not?

Authors: Interestingly, no hypothesis has yet been provided to explain the described pathological changes in the subchondral bone. Possible aetiopathologies of subchondral bone overgrowth include, but may not be limited to, impaired bone and articular cartilage regeneration, pathological vascularisation and angiogenesis, pathological structural consequences of altered biomechanical loading, hypertrophy of bone marrow-derived mesenchymal stem cells, and a disturbed mechanism of articular cartilage/ subchondral bone crosstalk. Differences in the interindividual intensity of their occurrence may explain in part why some osteochondral defects give rise to bone plate overgrowth and others do not. With regard to the formation of subchondral bone cysts, differences between animal species and humans have been described to account for the disparity in their development. In the sheep model, for example, there is a relatively high concentration of inflammatory cytokines (Benazzo et al., 2008) and activated matrix metalloproteinase-2 (Miyamoto et al., 2002) in the ovine synovial fluid when compared with the situation in humans. These factors, together with an elevated mean body temperature $\left(38-40{ }^{\circ} \mathrm{C}\right.$ ) (Igono et al., 1983; Recabarren et al., 1987) compared to humans, may favour the development of cysts in the subarticular spongiosa in sheep. In addition, the different biomechanical 
loading of the articular cartilage defect, based on differences in the range of motion and knee resting positions in various quadruped animal models compared to humans (Orth and Madry, 2013b; Pape and Madry, 2013), could also play a role. However, the definite reasons why some cartilage defects develop subchondral bone alterations while others do not (even in comparable animal models) will have to be further investigated in future studies.

Reviewer III: Concerning data in Table 2: do you think that the different frequency of bone plate overgrowth following microfracture reported by different orthopaedic surgeons could be related to surgical technique, i.e. different levels of aggressiveness in debridement of the lesion by each surgeon, or different surgical tools used to debride, prior to microfracture? Or, is it possible that the different clinical outcomes could be related to the different types of patients referred to the clinic (i.e., sports medicine versus more general population)?

Authors: Indeed, the different frequency of bone plate overgrowth following microfracture reported by different orthopaedic surgeons may be related to both the surgical technique and the heterogeneously distributed patient cohorts between the studies. With regard to the surgical technique, the work of Drobnic et al. (2010) has indeed demonstrated for the cartilage debridement step (prior to any marrow stimulation procedure or ACI) that the choice of surgical instrument critically affects the outcome with regard to completeness in cartilage removal and unintended injury of the subchondral bone plate. Likewise, aggressiveness in debridement or marrow stimulation would of course be another possible factor affecting the development of subchondral bone alterations. To date, no clinical study has yet evaluated the impact of patient age, degree of physical activity, etc. on the incidence of subchondral bone alterations during osteochondral repair. Although it has been shown that young patients with defects on the femoral condyles have the best prognostic factors for the microfracture treatment (Kreuz et al., 2006), it remains unknown which demographic factors favour the development of subchondral bone alterations. In conclusion, more high quality randomised controlled clinical trials will have to address these important questions in the future.

\section{Additional References}

Benazzo F, Cadossi M, Cavani F, Fini M, Giavaresi G, Setti S, Cadossi R, Giardino R (2008) Cartilage repair with osteochondral autografts in sheep: effect of biophysical stimulation with pulsed electromagnetic fields. J Orthop Res 26: 631-642.

Hunziker EB, Rosenberg LC (1996) Repair of partialthickness defects in articular cartilage: cell recruitment from the synovial membrane. J Bone Joint Surg 78A: 721-733.

Igono MO, Molokwu EC, Aliu YO (1983) Seasonal variations in rectal temperature of Yankasa sheep. Vet Res Commun 6: 223-226.

Klinger P, Surmann-Schmitt C, Brem M, Swoboda B, Distler JH, Carl HD, von der Mark K, Hennig FF, Gelse K (2011) Chondromodulin 1 stabilizes the chondrocyte phenotype and inhibits endochondral ossification of porcine cartilage repair tissue. Arthritis Rheum 63: 27212731.

Miyamoto K, Ishimaru J, Kurita K, Goss AN (2002) Synovial matrix metalloproteinase-2 in different stages of sheep temporomandibular joint osteoarthrosis. J Oral Maxillofac Surg 60: 66-72.

Orth P, Madry H (2013b) A low morbidity surgical approach to the sheep femoral trochlea. BMC Musculoskelet Disord 14: 5-12.

Pape D, Madry H (2013) The preclinical sheep model of high tibial osteotomy relating basic science to the clinics: standards, techniques and pitfalls. Knee Surg Sports Traumatol Arthrosc 21: 228-236.

Recabarren SE, Vergara M, Llanos AJ, Seron-Ferre M (1987) Circadian variation of rectal temperature in newborn sheep. J Dev Physiol 9: 399-408. 